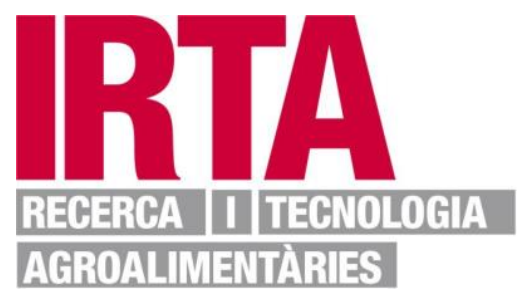

This document is a postprint version of an article published Food Chemistry () Elsevier after peer review. To access the final edited and published work see https://doi.org/10.1016/i.foodchem.2017.11.045 


\section{Oral bioaccessibility of toxic and essential elements in raw and cooked commercial seafood species available in European markets}

Ricardo N. Alves ${ }^{\mathrm{a}^{*}}$, Ana L. Maulvault ${ }^{\mathrm{a}, \mathrm{b}, \mathrm{c}}$, Vera L. Barbosa ${ }^{\mathrm{a}}$, Margarita Fernandez-Tejedor ${ }^{\mathrm{d}}$, Alice Tediosi ${ }^{\mathrm{e}}$, Michiel Kotterman ${ }^{\mathrm{f}}$, Fredericus H.M. van den Heuvel ${ }^{\mathrm{g}}$, Johan Robbens ${ }^{\mathrm{h}}$, José O. Fernandes ${ }^{\mathrm{i}}$ Rie Romme Rasmussen ${ }^{\mathrm{j}}$, Jens J. Sloth ${ }^{\mathrm{j}}$, António Marques ${ }^{\mathrm{a}, \mathrm{b}}$

${ }^{a}$ Division of Aquaculture and Upgrading (DivAV), Portuguese Institute for the Sea and Atmosphere (IPMA, I.P.), Lisbon, Portugal

${ }^{\mathrm{b}}$ Interdisciplinary Centre of Marine and Environmental Research (CIIMAR), University of Porto, Porto, Portugal

${ }^{\mathrm{c}}$ MARE - Marine and Environmental Sciences Centre, Faculty of Sciences, University of Lisbon (FCUL), Lisboa, Portugal

${ }^{\mathrm{d}}$ Marine Monitoring, Institute of Agriculture and Food Research \& Technology (IRTA), Sant Carles de la Ràpita, Tarragona, Spain

${ }^{\mathrm{e}}$ Aeiforia Srl, Gariga di Podenzano (PC), Italy

${ }^{\mathrm{f}}$ IMARES, Wageningen UR, AB Ijmuiden, The Netherlands

${ }^{g}$ Hortimare, Projects and Consultancy, J. Duikerweg 12B, 1703 DH Heerhugowaard, The Netherlands

${ }^{\mathrm{h}}$ Institute for Agricultural and Fisheries Research (ILVO), Merelbeke, Belgium

${ }^{i}$ LAQV-REQUIMT, Laboratory of Bromatology and Hydrology, Faculty of Pharmacy, University of Porto, Porto, Portugal

${ }^{j}$ National Food Institute, Technical University of Denmark, Søborg, Denmark

\section{*Corresponding author:}

Ricardo N. Alves - ricardo.alves@ipma.pt

Division of Aquaculture and Upgrading (DivAV)

Portuguese Institute for the Sea and Atmosphere (IPMA, I.P.), Lisbon, Portugal

e-mail contact:

RN Alves: ricardo.alves@ipma.pt

AL Maulvault: aluisa@ipma.pt

VL Barbosa: vera.barbosa@ipma.pt

M. Fernandez-Tejedor: margarita.fernandez@irta.cat

A. Tediosi: alice.tediosi@ aeiforia.eu

M. Kotterman: michiel.kotterman@wur.nl

F. H. M. van den Heuvel: freek.vd.heuvel@ hortimare.com

J. Robbens: Johan.Robbens@ilvo.vlaanderen.be

J. O. Fernandes: josefer@ff.up.pt

R. R. Rasmussen: riro@ food.dtu.dk

J. J. Sloth: jisl@food.dtu.dk

A.Marques: amarques@ipma.pt 


\begin{abstract}
The bioaccessibility of essential (zinc, selenium, copper, manganese, strontium, iron iodine) and toxic (mercury, methylmercury, arsenic, cadmium) elements was investigated in raw and cooked commercially available seafood species from European markets.
\end{abstract}

Bioaccessibility varied between seafood species and elements. Low MeHg bioaccessibility was observed in all species (10-60\%) and decreased significantly after steaming. Overall, As (> 64\%) were the toxic elements showing the highest bioaccessibility. Concerning essential elements bioaccessibility in raw seafood, Se (72.6 $\%)$ and $\mathrm{I}(70.5 \%)$ revealed the highest percentages, whereas $\mathrm{Fe}, \mathrm{Cu}$ and $\mathrm{I}(>73 \%)$ showed the highest bioaccessibility in steamed seafood. In addition, high selenium:methylmercury ratio and positive selenium health benefit values $\left(\mathrm{HBV}_{\mathrm{Se}}\right)$ were observed. The bioaccessibility of essential elements in steamed products increased or decreased according to species.

This study provides new insights and relevant toxicological data that will contribute to the establishment of new maximum permissible concentrations for toxic elements in seafood by the European food safety authorities, as well as recommended intakes for essential elements. These results will strengthen stakeholders' confidence towards commercially available seafood, and help consumers to wisely select what they eat in a more informed way. 


\section{Highlights:}

- Low MeHg bioaccessibility in seafood

- $\mathrm{MeHg}$ and $\mathrm{Cd}$ bioaccessibility decreased after steaming

- The bioaccessibility of essential elements increased (fish) and decreased (shellfish) after steaming

- The youngest segments of seaweed revealed higher levels of essential elements

- Fish, shellfish and seaweed species are good sources of essential elements

Keywords: seafood, toxic/essential elements, steaming, bioaccessibility

Abbreviations: $\mathrm{AL}$ - action of limits, ANOVA - analysis of variance, As - arsenic, $\mathrm{BD}$ - sample before digestion, $\mathrm{BIO}$ - bioaccessible fraction after in vitro digestion, $\mathrm{Cd}$ cadmium, CRM - certified reference biological material, CVD - cardiovascular diseases, $\mathrm{Cu}$ - copper, DORM-4 - dogfish muscle reference material, $\mathrm{Fe}$ - iron, $\mathrm{HBV}_{\mathrm{Se}}$ selenium health benefit value, $\mathrm{Hg}$ - mercury, ICP-MS - inductive coupled plasma mass spectrometer, I - iodine, LCn-3-PUFA - long chain polyunsaturated n-3 fatty acids, LOD - limit of detection, LOQ - limit of quantification, $\mathrm{MeHg}$ - methylmercury, Mn manganese, MPC - maximum permissible concentration, NBIO - non-bioaccessible fraction after in vitro digestion, RDAs - recommended dietary allowances, Se selenium, Se:Hg - Molar ratio between selenium and mercury, Se:MeHg - Molar ratio between selenium and methylmercury, $\mathrm{Sr}$ - strontium, TORT-2 - lobster hepatopancreas reference material, TWIs - tolerable weekly intakes, ULs - upper limits, WHO - World Health Organization, $\mathrm{Zn}$ - zinc 


\section{Introduction}

Seafood is considered an important dietary source of energy, proteins with high biological value and long chain polyunsaturated n-3 fatty acids (LCn-3-PUFA), (Larsen et al., 2011; Lund, 2013), which LCn-3-PUFA are considered as key players in the prevention against cardiovascular diseases (CVD), (He et al., 2004). The high nutritional value associated to seafood is also due to the presence of considerable amount of essential trace elements, including selenium (Se), iodine (I), iron (Fe), zinc $(\mathrm{Zn})$, copper $(\mathrm{Cu})$ and manganese $(\mathrm{Mn})$. Essential elements are generally involved in metabolism and several biological processes acting as cofactors of enzymes (Celik and Oehlenschlager, 2007; Fraga, 2005). A balanced diet based on seafood has been extensively recommended due to its health benefits (Larsen et al., 2011).

Nevertheless, marine seafood can also accumulate high levels of chemical contaminants, including toxic elements such as cadmium $(\mathrm{Cd})$, mercury $(\mathrm{Hg})$, arsenic (As) and lead $(\mathrm{Pb})$, raising human health-related concerns (Maulvault et al., 2015; Vazquez et al., 2015). The World Health Organization (WHO) defined these four toxic elements as toxic chemicals of major public health concern (WHO, 2012), and the European Safety Authority (EFSA) has in recent years published toxicological guidelines for these toxic elements (EFSA, 2009a, 2009b, 2012).

Regulatory authorities and the scientific community have been focusing their attention on these toxic and essential elements in seafood (Vandermeersch et al., 2015; Vazquez et al., 2015). Within the group of toxic elements, methylmercury ( $\mathrm{MeHg}$ ) is the mercury compound most commonly found in fish, being recognized as a neurotoxic and carcinogenic pollutant. Due to the high stability and long-term elimination from tissues (Chapman and Chan, 2000), this persistent pollutant has been one of the most studied contaminants, and high concentrations are usually associated with predatory and 
carnivorous fish species (Costa et al., 2016; Zmozinski et al., 2014). Several studies have shown that Se has an ability to decrease the toxicity of $\mathrm{MeHg}$, and the molar ratio between Se and MeHg (Se:MeHg), and Se health benefit values $\left(\mathrm{HBV}_{\mathrm{Se}}\right)$ has been used to assess Se-dependent health benefits and the impact of $\mathrm{Hg}$ exposure in seafood (Cabanero et al., 2007; Ralston et al., 2016).

The total contaminant concentration detected in seafood does not always reflect the amount of the contaminant that will become available for absorption at the intestinal epithelium level, defined as bioaccessibility. Bioaccessibility is an important tool to estimate the oral availability, i.e. the proportion of the bioaccessible fraction that potentially reaches the systemic circulation (Collins et al., 2015; Versantvoort et al., 2005). The assessment of bioaccessibility is fundamental for risk-benefit analysis of nutrients and contaminants associated to food consumption, providing more accurate information and guidelines for food consumption to authorities, industry and consumers (Cardoso et al., 2013; Maulvault et al., 2013; Maulvault et al., 2011). Several in vitro models were developed to simulate the gastrointestinal digestion process in humans (Cardoso et al., 2015; Marques et al., 2011; Minekus et al., 2014). These in vitro digestion methodologies have been used to evaluate essential and toxic elements bioaccessibility in seafood, mainly in molluscs and fish. Most studies on the bioaccessibility of essential and toxic elements were performed in raw products, despite most seafood is only consumed after culinary preparation. Therefore, risk assessment of chemical contaminants is currently evaluated mainly for raw seafood products, potentially becoming a bottleneck in public health safety guidelines (Cardoso et al., 2010; Maulvault et al., 2013). Recent studies described the effect of culinary treatments in $\mathrm{MeHg}$ bioaccessibility, and indeed it has been demonstrated that culinary treatment generally reduces toxic elements bioaccessibility in seafood (e.g. mercury) (Cano- 
Sancho et al., 2015; Matos et al., 2015; Ouedraogo and Amyot, 2011). Furthermore, the existing information regarding the effects of culinary treatments in essential and toxic elements bioaccessibility from seafood species available in European markets is still scarce.

In this context, this study aims to: (1) assess the bioaccessibility of several essential (Zn, Se, Cu, Mn, Sr, I, Fe) and toxic (Hg, MeHg, As, Cd) elements in marine seafood species (including fish, molluscs, crustaceans and seaweed) available in different European markets; (2) evaluate the effects of culinary treatment (steaming) on the bioaccessibility of essential/toxic elements; (3) explore the correlation between the elements bioaccessibility and the overall concentration in seafood; and (4) evaluate the differences in bioaccessibility of the analysed elements according to seafood type.

\section{Material and methods}

\subsection{Sampling species and culinary treatment}

Nine seafood species were collected in different European markets including hake (Merlucius australis), tuna (Katsuonus pelamis), monkfish (Lophius piscatorius), mackerel (Scomber scombrus), plaice (Pleuronectes platessa), mussel (Mytilus edulis), octopus (Octopus vulgaris), shrimp (Litopenaeus vannamei) and a seaweed species (Laminaria digitata). All samples were collected in different seasons between April 2014 and November 2015. For each species, specimens were of commercial sizes, with uniform sizes and weights. Origin, market country, number of specimens, total length (mean $\mathrm{mm})$ and total weight $(\mathrm{g})($ mean $\pm \mathrm{SD})$ and moisture $(\%)$ are described in Table 1. 
Table 1.

Selected species from European seafood markets used for the essential and toxic elements bioaccessibility assessment.

\begin{tabular}{|c|c|c|c|c|c|c|c|c|}
\hline \multirow{2}{*}{ Seafood } & \multirow{2}{*}{ Species } & \multirow{2}{*}{ Origin } & \multirow{2}{*}{ Market country } & \multirow{2}{*}{$n$} & \multirow{2}{*}{$\begin{array}{l}\text { Total length } \\
\text { (mm) }\end{array}$} & \multirow{2}{*}{ Total weight (g) } & \multicolumn{2}{|c|}{ Moisture (\%) } \\
\hline & & & & & & & Raw & Steamed \\
\hline Hake & Merlucius australis & Pacific Ocean & Portugal & 25 & n.a & $2,500-3,500$ & 74.66 & 67.13 \\
\hline Tuna & Katsuwonus pelamis & Pacific Ocean & Portugal & 25 & n.a & $>3,400$ & 67.6 & 56.2 \\
\hline Monkfish & Lophius piscatorius & Atlantic Ocean & Portugal & 25 & $570-590$ & $3,365-3,448$ & 82.41 & 77.17 \\
\hline Mackerel & Scomber scombrus & Adriatic Sea & Italy & 25 & $189-285$ & $47.7-268.7$ & 75.2 & 72.5 \\
\hline Plaice & Pleuronectes platessa & North Sea & The Netherlands & 25 & $347-411$ & $376-635$ & n.d & n.d \\
\hline Mussel & Mytilus edulis & Atlantic Ocean & The Netherlands & 50 & $44-68$ & $5.9-18.5$ & n.d & n.d \\
\hline Octopus & Octopus vulgaris & Mediterranean & Spain & 25 & $920^{1}$ & $2,600^{2}$ & 80.1 & 72.66 \\
\hline Shrimp & $\begin{array}{c}\text { Litopenaeus } \\
\text { vannamei }\end{array}$ & Indic Ocean & Portugal & 50 & $11-14$ & $11-28$ & n.d & n.d \\
\hline Seaweed & Laminaria digitata & North Sea & Norway & 20 & n.a & n.a & n.d & n.d \\
\hline
\end{tabular}

$\mathrm{n}$, number of specimens analyzed; total length $(\mathrm{mm})$ and total weight $(\mathrm{g})$ - range minimum and maximum; ${ }^{1}$ total length (mm) presented as mean; ${ }^{2}$ total weight $(\mathrm{g})$ presented as mean; n.a, data not available; n.d, not determined. 
For fish, muscle tissue was collected without skin from 25 specimens. For cephalopods $(n=25)$ and crustaceans $(n=50)$, mantle and abdominal muscle tissue were sampled, respectively. The edible part with the intervalvar liquid of bivalves was collected from 50 individuals, whereas in seaweed, only the frond (leaf) was collected from 20 L. digitata specimens, separating the newer part of the leafs (closer to the stipe and designated hereafter as new) and the older part of the leafs (more distant to the stipe and designated as old).

Each sample was divided into two portions, one used for the culinary treatment (steaming at $105^{\circ} \mathrm{C}$ wrapped up in aluminium foil), and one for raw assessment. Fish, cephalopods and seaweeds were steamed for 15 minutes whereas bivalves and crustaceans were steamed for 5 minutes. Raw and steamed samples were homogenised with a grinder (Retasch Grindomix GM200, Germany) using polypropylene cups and stainless steel knives at 5,000 rpm until complete visual disruption of the tissue and further kept at $-20^{\circ} \mathrm{C}$ until the in vitro digestion.

\subsection{In vitro human digestion model}

\subsubsection{Reagents}

The reagents used to prepare the digestion fluids solution were the following: Inorganic: $\mathrm{NaCl}($ Merck, $99.5 \% \mathrm{~m} / \mathrm{v}), \mathrm{NaHCO}_{3}($ Merck, $99.5 \% \mathrm{~m} / \mathrm{v}), \mathrm{CaCl}_{2} .2 \mathrm{H}_{2} \mathrm{O}$ (Sigma, C3881), KCl (Merck, 99.5\% m/v), KSCN (Sigma, P2713), $\mathrm{NaH}_{2} \mathrm{PO}_{4}$ (Merck, 99.5\% m/v), $\mathrm{Na}_{2} \mathrm{SO}_{4}$ (Merck, $90 \%$ m/v), $\mathrm{NH}_{4} \mathrm{Cl}$ (Riedel-de Haen, $99.5 \% \mathrm{~m} / \mathrm{v}$ ), $\mathrm{KH}_{2} \mathrm{PO}_{4}$ (Merck, 99.5\%), $\mathrm{MgCl}_{2}$ (Riedel-de Haen, 99.5\% m/v), $\mathrm{HCl}$ (Merck, 37\% m/v); Organic: urea (Sigma, U5128), glucose (Sigma, G5400), glucuronic acid (Sigma, 
G5269), D-(+)-Glucosamine hydrochloride (Sigma, G4875), uric acid (Sigma, U2625), albumin from bovine serum (Sigma, A7906), $\alpha$-amylase, from Aspergillus oryzae (Sigma, 86250), mucin from porcine stomach (Sigma, M2378), pepsin from porcine stomach mucosa (Sigma, P7125), lipase from porcine pancreas, type II (Sigma, L3126), pancreatin from porcine pancreas (Sigma, P8096), trypsin from porcine pancreas (Sigma, T6567), $\alpha$-chymotrypsin from bovine pancreas (Sigma, C4129) and bile porcine extract (Sigma, B8631).

\subsubsection{In vitro digestion protocol}

The in vitro digestion protocol used to study the elements bioaccessibility was described in Braga et al. (2016) and schematized in Supplementary Fig. S1. The in vitro digestion protocol adapted from Versantvoort et al. (2005) and Minekus et al. (2014) was used to assess the elements bioaccessibility. Raw and steamed seafood samples were in vitro digested in triplicate with four digestion fluids: saliva, gastric, duodenal and bile. Each digestion fluid is composed by several inorganic and organic components (Supplementary Table S1).

Briefly, for each homogenized sample, 1.5 to 2.0 grams were digested in triplicate (Nalgene ${ }^{\mathrm{TM}}$ high-speed PPCO centrifuge tubes) at $37^{\circ} \mathrm{C}$ using a Rotary Tube Mixer with Disc (25 rpm; LSCI, Portugal) inserted in an incubator. The digestion was performed using the following protocol: oral phase ( $4 \mathrm{ml}$ of saliva fluid for $5 \mathrm{~min}$ at $\mathrm{pH}$ $7.0 \pm 0.2)$, gastric phase ( $8 \mathrm{~mL}$ of gastric fluid for 2 hrs at $\mathrm{pH} 2 \pm 0.2)$ and intestinal phase ( $8 \mathrm{~mL}$ of duodenal fluid and $4 \mathrm{~mL}$ of bile fluid for 2 hrs at $\mathrm{pH} 7 \pm 0.2$ ). To avoid enzyme degradation/inhibition, each digestion fluid was prepared just before starting the digestion protocol. In each digestion phase, $\mathrm{pH}$ was adjusted immediately before the 
digestion. In the end, reaction tubes were placed on ice, and centrifuged at 2,750x $\mathrm{g}$ at $10^{\circ} \mathrm{C}$ for 10 minutes to separate the bioaccessible fraction (BIO) from the sample residues (non-bioaccessible fraction - NBIO).

\subsubsection{Digestion efficiency}

To assess the in vitro digestion efficiency, total protein levels were determined using an FP-528 DSP LECO nitrogen analyser (LECO, St. Joseph, USA). Protein levels were measured in wet weight (raw and steamed) - before digestion (BD), and in the bioaccessible (BIO) and non-bioaccessible (NBIO) fractions. The calibration standard curve was performed with EDTA following the methodology described by Saint-Denis \& Goupy (2004).

Protein recovery $(\%)$ was defined as the following ratio:

$$
(\mathrm{BIO}+\mathrm{NBIO}) \times 100 / \mathrm{BD},
$$

where $\mathrm{BIO}+\mathrm{NBIO}$ are the sum of protein levels detected in the bioaccessible (BIO) and non-bioaccessible (NBIO) fractions, and BD is the amount of protein detected in the sample before digestion.

Bioaccessible protein (\%) was defined as the following ratio:

\section{$\mathrm{BIO} \times 100 / \mathrm{BD}$}

where BIO corresponds to the protein levels detected in the bioaccessible fraction $(\mathrm{BIO})$, and $\mathrm{BD}$ is the amount of protein detected in sample before digestion. 


\subsection{Essential and toxic element analysis}

\subsubsection{Mercury and methylmercury}

Bioaccessibility of total mercury $(\mathrm{Hg})$ and methylmercury $(\mathrm{MeHg})$ was assessed in several seafood species including hake, tuna, mackerel, monkfish and octopus. $\mathrm{Hg}$ levels in the remaining species were below the limit of quantification. The methodology used to extract $\mathrm{MeHg}$ has been previously described by Maulvault et al. (2015). Briefly, each BD sample was freeze-dried (at $-50{ }^{\circ} \mathrm{C}$, low pressure $-10^{-1} \mathrm{~atm}$ ) for $\mathrm{MeHg}$ analysis prior to the in vitro digestion. Then, approximately $150 \mathrm{mg}$ of $\mathrm{BD}$ sample, and $5 \mathrm{~g}$ of BIO were hydrolysed with hydrobromic acid $(10 \mathrm{~mL}, 47 \% \mathrm{w} / \mathrm{w}$; Merck), and then MeHg extraction was performed with two steps of purification with toluene (99.8\% w/w, Merck). In the end, cysteine solution (1\% L-cystein chloride in $12.5 \%$ anhydrous sodium sulphate and $0.8 \%$ sodium acetate) was added to extract MeHg (Scerbo and Barghigiani, 1998). Hg and MeHg (through cysteine extracts) levels were determined by atomic absorption spectrometry using the $\mathrm{Hg}$ analyser (Leco, AMA 254, St. Joseph, MI, USA). This technique is based on $\mathrm{Hg}$ cold vapour generation, where samples are decomposed by combustion. Subsequently, $\mathrm{Hg}$ is concentrated by amalgamation with gold and detected at $254 \mathrm{~nm}$. Mercury concentrations were calculated from linear calibration with a $\mathrm{Hg}$ (II) nitrate standard solution $\left(1,000 \mathrm{mg} \mathrm{L}^{-1}\right.$, Merck) diluted in nitric acid $\left(0.5 \mathrm{~mol} \mathrm{~L}^{-1}\right.$, Merck). For total $\mathrm{Hg}, 10 \mathrm{mg}$ of wet weight $\mathrm{BD}$ or $\mathrm{NBIO}$, and 100 to $800 \mu \mathrm{l}$ of $\mathrm{BIO}$ were used.

Total $\mathrm{Hg}$ recovery (\%) was defined as the following ratio:

$$
(\mathrm{Hg} \mathrm{BIO}+\mathrm{Hg} \mathrm{NBIO}) \times 100 / \mathrm{Hg} \mathrm{BD},
$$


where $\mathrm{Hg} \mathrm{BIO}+\mathrm{Hg} \mathrm{NBIO}$ are the sum of $\mathrm{Hg}$ levels detected in $\mathrm{BIO}$ and $\mathrm{NBIO}$ fractions, and $\mathrm{Hg} \mathrm{BD}$ is the amount of $\mathrm{Hg}$ detected in $\mathrm{BD}$ sample.

Bioaccessible $\mathrm{Hg}$ (MeHg) (\%) was defined as the following ratio:

Hg (MeHg) BIO x $100 /$

Hg (MeHg) BD ,

where $\mathrm{Hg}(\mathrm{MeHg}) \mathrm{BIO}$ corresponds to $\mathrm{Hg}$ levels detected in $\mathrm{BIO}$, and $\mathrm{Hg}$

(MeHg) BD is the amount of $\mathrm{Hg}(\mathrm{MeHg})$ levels detected in BD sample.

2.3.2. Zinc, selenium, copper, manganese, strontium, iodine, iron, arsenic and cadmium

Bioaccessibility of $\mathrm{Zn}, \mathrm{Se}, \mathrm{Cu}, \mathrm{Mn}, \mathrm{Sr}, \mathrm{I}, \mathrm{Fe}$, As and $\mathrm{Cd}$ was assessed in different seafood matrices, including hake, tuna, mackerel, monkfish, plaice, octopus, mussel, shrimp and seaweed (old and new segments).

The water used was ultra-purified $(<18 \mathrm{M} \Omega \mathrm{cm})$ using a Milli-Q-Integral system (Millipore, Milford, MA, USA) and all reagents used were "per analysis" quality or better. Nitric acid $\left(\mathrm{HNO}_{3}\right)$ and hydrochloric acid $(\mathrm{HCl})$ (PlasmaPure, SCP Science, Courtaboeuf, France) were used for sample preparation and analysis. Standard stock solutions of all elements were prepared at $1000 \mathrm{mg} \mathrm{ml}^{-1}$ (PlasmaCal, SCP Science, Courtaboeuf, France).

For $\mathrm{Zn}, \mathrm{Se}, \mathrm{Cu}, \mathrm{Mn}, \mathrm{Sr}, \mathrm{Fe}, \mathrm{As}$ and $\mathrm{Cd}$, subsamples of seafood before digestion (1.0 g wet weight), BIO fraction $(1.0 \mathrm{ml})$ and CRM (0.20 g dry weight) were digested in closed vessels in a microwave oven (MARS5, CEMNC, USA) with $4 \mathrm{ml}$ nitric acid (65\% v/v, Merck) and $2 \mathrm{ml}$ hydrogen peroxide (30\% v/v, Merck). The digests were diluted to a volume of $25 \mathrm{ml}$ with milliQ water. Prior to analysis sample aliquots were further diluted (seafood: 5 and 100 times; digestive solutions: 2 times; and CRM 
extracts: 5 and 50 times) resulting in $2 \% \mathrm{HNO}_{3}$ and $1 \% \mathrm{HCl}(\mathrm{w} / \mathrm{v})$ aqueous measurement solutions.

For iodine (I), subsamples of homogenized seafood BD, NBIO (1.0 g of wet sample) and BIO fraction $(1.0 \mathrm{ml})$ were digested with the alkaline tetramethylammonium hydroxide $\left(25 \%\right.$ w/w; TMAH $=\left(\mathrm{CH}_{3}\right) 4 \mathrm{~N}^{+} \mathrm{OH}^{-}, 99.9999 \%$, Thermofisher, Germany) reagent. Samples were homogenized with MilliQ water. $1 \mathrm{~mL}$ of TMAH was added to the samples, mixed thoroughly and incubated at $90 \pm 3{ }^{\circ} \mathrm{C}$ during $3 \mathrm{~h}$. After cooling, the digests were diluted to a volume of $25 \mathrm{ml}$ with MilliQ water.

An inductive coupled plasma mass spectrometer (ICP-MS) (Agilent 8800 ICPQQQ-MS, Santa Clara, USA) equipped with a micromist concentric quartz nebulizer and a Scott type double-pass water-cooled spray chamber was run in no gas $(\mathrm{Cd}$,$) ,$ helium ( $\mathrm{Zn}, \mathrm{Se}, \mathrm{Cu}, \mathrm{Mn}, \mathrm{Sr}$ and $\mathrm{Fe}$ ) and oxygen (As (mass shift 75->91) mode, respectively, with $0.2 \mathrm{sec}$ integration time per mass. Typical plasma conditions were $1550 \mathrm{~W}$ RF power, $15 \mathrm{~L} \mathrm{~min}^{-1}$ plasma gas, $1.05 \mathrm{~L} / \mathrm{min}$ carrier gas and $0 \mathrm{~L} \mathrm{~min}^{-1}$ makeup gas. Cell gas flows were $5 \mathrm{~mL} \mathrm{~min}^{-1}$ for helium and $30 \%$ oxygen with stabilization times of $30 \mathrm{~s}, 10 \mathrm{~s}$ and $30 \mathrm{~s}$ for helium, no gas, and oxygen mode, respectively. The auto sampler (ASX-500, Agilent Technologies, Waldbronn, Germany) introduced the samples into the ICP-MS with a sample uptake time of $50 \mathrm{sec} .(0.4 \mathrm{rps})$ and a stabilization time of $40 \mathrm{sec}(0.1 \mathrm{rps})$. Rinse programme between samples: Port (water) $10 \mathrm{~s}(0.2 \mathrm{rps})$, succeeded by rinsing in $2 \% \mathrm{HNO}_{3} \mathrm{w} / \mathrm{v}$ during $30 \mathrm{sec}(0.1 \mathrm{rps})$ and $60 \mathrm{sec}$ (0.4 rps). Internal standard (ISTD) was added on-line $\left(5 \mu \mathrm{g} \mathrm{L}^{-1} \mathrm{Rh}\right.$ and $\left.\mathrm{Bi}\right)$ via a t-piece using a peristaltic pump.

The determination of iodine was performed in a separate analytical sequence using the same instrumental settings as above with iodine analysed in no-gas mode and 
using tellurium (Te) as internal standard. All calibration solutions were diluted in $0,25 \%$ TMAH using an iodine stock solution $(999 \mu \mathrm{g} / \mathrm{ml}$ ammonium iodide, Teknolab, Sweden). The rinse programme between samples was as follows: port (water) $10 \mathrm{~s}$. (0.2 rps) succeeded by rinse steps 1 and $2(0.25 \% \mathrm{TMAH} \mathrm{c} / \mathrm{v}) 30 \mathrm{sec}(0.1 \mathrm{rps})$ and $60 \mathrm{sec}$ (0.4 rps), respectively.

A low calibration standard was repeatedly analysed throughout the sequence sequence in order to verify instrument stability. Blank samples were analysed together with the samples and subtracted to all results. The LOD was assigned to the detection limit $(\mathrm{DL})$ of the calibration curve $(\mathrm{DL}=3 \times$ standard deviation $(\sigma)$ of response at the zero concentration level) and the LOQ was calculated as ( $3 \times$ LOD). The quantification was done by external linear calibration (ng/ml: Cd (0.01-6), and As (0.15-200).

Essential and toxic elements in the bioaccessible fraction $(\%)$ were calculated as the following ratio:

\section{E BIO x 100/E BD,}

where $\mathrm{E} \mathrm{BIO}$ corresponds to the element levels detected in $\mathrm{BIO}$ fraction, and $\mathrm{E}$ $\mathrm{BD}$ is the amount of element detected in the sample before digestion.

\subsubsection{Quality control}

Replicate measurements were done for each sample. The detection limits for each element are given in Table 2. Certified reference material (CRM), Lobster hepatopancreas - TORT-2 (lobster hepatopancreas) and DORM-4 (fish muscle) (both National Research Council Canada, Ontario, Canada) was used to check the method accuracy for $\mathrm{Hg}, \mathrm{MeHg}, \mathrm{Zn}, \mathrm{Se}, \mathrm{I}, \mathrm{Cu}, \mathrm{Mn}, \mathrm{Sr}, \mathrm{Fe}, \mathrm{As}$ and $\mathrm{Cd}$ quantification. Detailed information on the quality assurance data can be found in Table 2 . 
Table 2.

Target values (certificate \pm range) and mean measured concentrations ( $\mathrm{mg} / \mathrm{kg}$ dry weight) and the associated relative standard deviation (RSD) in certified reference materials (CRM). For all elements mean values were reported for CRM samples extracted in duplicates and analysed in two dilutions (5 and 50 times) except for iodine, $\mathrm{Hg}$ and $\mathrm{MeHg}$ were extracted in duplicates and analysed. Limits of detection (LOD) for each element in the seafood sample before digestion (BD) and in the bioaccessible fraction (BIO).

\begin{tabular}{|c|c|c|c|c|c|c|c|c|}
\hline \multirow[b]{2}{*}{ Element } & \multicolumn{5}{|c|}{ CRM } & \multicolumn{3}{|c|}{ LOD } \\
\hline & Type & $\begin{array}{c}\text { Certificate } \\
(\mathrm{mg} / \mathrm{kg})\end{array}$ & $\begin{array}{c}\text { Measured } \\
(\mathrm{mg} / \mathrm{kg}) \\
\end{array}$ & $\begin{array}{l}\text { RSD } \\
(\%)\end{array}$ & $\begin{array}{c}\text { Recovery } \\
(\%)\end{array}$ & $\begin{array}{c}\text { Measure-ment solution } \\
(\mathrm{ng} / \mathrm{ml})\end{array}$ & $\begin{array}{c}\text { Raw or steamed seafood } \\
\text { (BD) } \\
(\mathrm{ng} / \mathrm{g}) \\
\end{array}$ & $\begin{array}{c}\text { Bioacces-sible fraction } \\
\text { (BIO) } \\
\text { (ng/ml) } \\
\end{array}$ \\
\hline $\mathrm{Hg}$ & TORT-2 & $0.27 \pm 0.06$ & $0.332 \pm 0.004$ & 1 & 123 & $1.93-3.24$ & $1.93-3.24$ & $1.93-3.24$ \\
\hline MeHg & TORT-2 & $0.152 \pm 0.013$ & $0.140 \pm 0.009$ & 6 & 92 & $1.93-3.24$ & $1.93-3.24$ & $1.93-3.24$ \\
\hline As & $\begin{array}{l}\text { DORM-4 } \\
\text { TORT-2 }\end{array}$ & $\begin{array}{c}6.80 \pm 0.64 \\
21.6 \pm 1.8 \\
\end{array}$ & $\begin{array}{c}6.73 \\
22 \\
\end{array}$ & $\begin{array}{l}1 \\
1\end{array}$ & $\begin{array}{c}99 \\
102 \\
\end{array}$ & 0.06 & 8 & 3 \\
\hline Cd & $\begin{array}{l}\text { DORM-4 } \\
\text { TORT-2 }\end{array}$ & $\begin{array}{c}0.306 \pm 0.015 \\
26.7 \pm 0.6 \\
\end{array}$ & $\begin{array}{c}0.317 \\
28.5 \\
\end{array}$ & $\begin{array}{l}3 \\
0\end{array}$ & $\begin{array}{l}104 \\
107 \\
\end{array}$ & 0.0003 & 0.04 & 0.02 \\
\hline Zn & $\begin{array}{l}\text { DORM-4 } \\
\text { TORT-2 }\end{array}$ & $\begin{array}{c}52.2+/-3.2 \\
180+/-6 \\
\end{array}$ & $\begin{array}{l}51.8 \\
188 \\
\end{array}$ & $\begin{array}{l}6 \\
3 \\
\end{array}$ & $\begin{array}{c}99 \\
104 \\
\end{array}$ & 1.22 & 153 & 61 \\
\hline Se & $\begin{array}{l}\text { DORM-4 } \\
\text { TORT-2 }\end{array}$ & $\begin{array}{l}3.56+/-0.34 \\
5.63+/-0.67 \\
\end{array}$ & $\begin{array}{l}3.58 \\
5.51 \\
\end{array}$ & $\begin{array}{l}8 \\
6 \\
\end{array}$ & $\begin{array}{c}101 \\
98 \\
\end{array}$ & 0.16 & 20 & 8 \\
\hline $\mathbf{C u}$ & $\begin{array}{l}\text { DORM-4 } \\
\text { TORT-2 }\end{array}$ & $\begin{array}{c}15.9+/-0.9 \\
106+/-10 \\
\end{array}$ & $\begin{array}{l}16.3 \\
103 \\
\end{array}$ & $\begin{array}{c}10 \\
5 \\
\end{array}$ & $\begin{array}{c}103 \\
97 \\
\end{array}$ & 0.11 & 14 & 5.5 \\
\hline Mn & $\begin{array}{l}\text { DORM-4 } \\
\text { TORT-2 }\end{array}$ & $\begin{array}{c}- \\
13.6+/-1.2 \\
\end{array}$ & $\begin{array}{c}3 \\
13.4 \\
\end{array}$ & $\begin{array}{l}8 \\
4 \\
\end{array}$ & $\begin{array}{c}- \\
99 \\
\end{array}$ & 0.65 & 81 & 32.5 \\
\hline $\mathbf{S r}$ & $\begin{array}{l}\text { DORM-4 } \\
\text { TORT-2 }\end{array}$ & $\begin{array}{c}- \\
45.2+/-1.9 \\
\end{array}$ & $\begin{array}{l}7.88 \\
43.9 \\
\end{array}$ & $\begin{array}{l}5 \\
5 \\
\end{array}$ & 97 & 0.16 & 20 & 8 \\
\hline $\mathbf{I}$ & $\begin{array}{l}\text { DORM-4 } \\
\text { TORT-2 } \\
\text { Seaweed* }\end{array}$ & $\begin{array}{c}- \\
- \\
631+/ 47\end{array}$ & $\begin{array}{c}2.75 \\
44.71 \\
587 \\
\end{array}$ & $\begin{array}{l}1 \\
2 \\
1\end{array}$ & $\begin{array}{c}- \\
- \\
93\end{array}$ & 0.04 & 4 & 4 \\
\hline $\mathbf{F e}$ & $\begin{array}{l}\text { DORM-4 } \\
\text { TORT-2* }\end{array}$ & $\begin{array}{l}341+/-27 \\
105+/-13\end{array}$ & $\begin{array}{l}364 \\
105 \\
\end{array}$ & $\begin{array}{l}4 \\
7 \\
\end{array}$ & $\begin{array}{l}107 \\
100 \\
\end{array}$ & 5.44 & 680 & 272 \\
\hline
\end{tabular}

* Material characterized in a collaborative trial (CENFEEDiod-S1). 
2.3.4. Se:Hg and Se:MeHg molar ratios and Selenium Health Benefit Value ( $\left.\mathrm{HBV}_{\mathrm{Se}}\right)$

Se:Hg and Se:MeHg molar ratios were calculated by converting $\mathrm{Se}, \mathrm{Hg}$ and

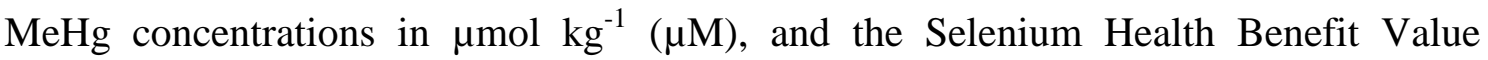
$\left(\mathrm{HBV}_{\mathrm{Se}}\right)$ was determined according to Raltson \& Raymond (2014).

$$
\mathrm{HBV}_{\mathrm{Se}}=\frac{\mathbf{s e}-\mathbf{H g}(\mathrm{MeHg})}{\mathrm{Se}} *(\mathrm{Se}+\mathbf{H g}(\mathbf{M e H g}))
$$

where $\mathrm{Se}$ and $\mathrm{Hg}$ (or $\mathrm{MeHg}$ ) were the concentrations expressed in $\mu \mathrm{mol} / \mathrm{kg}$.

\subsubsection{Benefit-Risk balance}

Percentages of recommended dietary allowances (RDAs) for $\mathrm{Zn}, \mathrm{Se}, \mathrm{Cu}, \mathrm{I}, \mathrm{Fe}$, as well as of action limits (AL) set for Mn were calculated according to reference values set by the US National Academy of Sciences for individual adults aged between 19 and 50 (USNAS, 2010) and considering a daily meal composed by $150 \mathrm{~g}$ of seafood (raw or cooked). A smaller portion (i.e. $50 \mathrm{~g}$ ) was considered for seaweed given the fact that vegetable food items are usually consumed as a side dish. Strontium was not considered in this analysis, as no reference value is available for the intake of this element. In cases where the percentage of RDA was above $100 \%$, upper tolerable levels (ULs), i.e. maximum levels of intake of essential elements unlikely to result in adverse effects to the general population, were also calculated.

The percentage of tolerable weekly intakes (TWIs) for $\mathrm{MeHg}$ and $\mathrm{Cd}$ accomplished with the consumption of $150 \mathrm{~g}$ of fish, mollusks and crustaceans or $50 \mathrm{~g}$ of seaweeds were also calculated according to the values established by EFSA (2011, 2012), and considering an average adult body weight (bw) of $70 \mathrm{~kg}$. Arsenic was not included in 
the analysis since the reference value set by EFSA only concerns the intake inorganic As (As speciation not analysed in the present study). Furthermore, the last Scientific Opinion released by EFSA suggested that, given the recent toxicological data on this toxic element, the previous provisional TWI (PTWI $=15 \mu \mathrm{g} \mathrm{kg}^{-1}$ bw) set for iAs requires update (EFSA, 2009).

Calculations regarding RDAs (and ALs), ULs, as well as TWIs were performed either including or excluding elements' bioaccessibility.

\subsubsection{Statistical analysis}

Differences in elements concentration, bioaccessibility, Se:Hg, Se:MeHg and $\mathrm{HBV}_{\mathrm{Se}}$ between samples and between raw and steamed seafood were analyzed by Twoway ANOVA with the significance level set at $5 \%$ using SigmaPlot v10.0 (Systat Software, Inc., CA, USA) after checking for normality and variance homogeneity. Tukey's post-hoc test was used for pair wise multiple comparisons. When ANOVA assumptions were not met, ANOVA by Ranks followed by Dunn's test for pairwise comparisons was performed. Statistical significance was set at $\mathrm{p}<0.05$. Additionally, for each element the regression coefficient between the total element concentration and bioaccessibility was analysed by SigmaPlot v10.0 (Systat Software, Inc., CA, USA).

\section{Results}

\section{$\underline{\text { 3.1. Elements in raw seafood }}$}


Concentrations of toxic elements $\mathrm{Hg}, \mathrm{MeHg}$, $\mathrm{As}$ and $\mathrm{Cd}$ were determined in seafood species. Hg concentration varied between 0.146 (mackerel) and $0.376 \mu \mathrm{g} \mathrm{g}^{-1}$ ww (octopus). MeHg concentration in seafood ranged between $0.079 \mu \mathrm{g} \mathrm{g}^{-1}$ ww (mackerel) and $0.266 \mu \mathrm{g} \mathrm{g}^{-1} \mathrm{ww}$ (octopus). $\mathrm{Hg}$ and $\mathrm{MeHg}$ varied according to the following order: octopus $>$ hake $>$ monkfish $>$ tuna $>$ mackerel, $(\mathrm{p}<0.05)$, (Fig. 1, Supplementary Table S2). The highest and lowest As levels were observed in octopus and shrimp, respectively. Significant differences were observed between the two seaweed leaf portions $(\mathrm{p}<0.001)$, with the oldest part showing higher As levels $(12.0$ $\mu \mathrm{g} \mathrm{g}^{-1}$ ww.) (Fig. 1, Supplementary Table S2). Fig. 1 reveals that Cd concentration in seafood ranged between 1.03 (monkfish) and 72.8 (mussel) $\mu \mathrm{g} \mathrm{kg}^{-1}$ ww. Higher Cd levels were observed in bivalves, crustaceans and seaweed compared to fish $(\mathrm{p}<0.05)$. In relation to seaweed, the old segment revealed 50 times higher $\mathrm{Cd}$ levels than those observed in the newer part $(\mathrm{p}<0.001)$ (Supplementary Table S2).

In general, molluscs and crustaceans showed the highest levels of $\mathrm{Zn}, \mathrm{Cu}, \mathrm{Mn}$ and Fe, whereas seaweed was the richest seafood in I and Sr. Hake showed the lowest concentration of most elements ( $\mathrm{Zn}, \mathrm{Cu}, \mathrm{Mn}, \mathrm{Sr}, \mathrm{I}, \mathrm{Fe})$. Tuna showed high concentration of $\mathrm{Zn}, \mathrm{Se}, \mathrm{Fe}$ and $\mathrm{Cu}$ (Fig. 1, Supplementary Table S3). The highest $\mathrm{Zn}$ concentrations were found in shrimp $\left(18.4 \mu \mathrm{g} \mathrm{g}^{-1} \mathrm{ww}\right)$, whereas the lowest $\mathrm{Zn}$ concentration was registered in hake $\left(2.91 \mu \mathrm{g} \mathrm{g}^{-1} \mathrm{ww}\right)$. The Se content ranged between $<0.020$ (seaweeds) and $2.076 \pm 0.02 \mu \mathrm{g} \mathrm{g}^{-1} \mathrm{ww}$ (tuna), (Fig. 1, $\mathrm{p}<0.05$ ). Shrimp $\left(8.78 \mu \mathrm{g} \mathrm{g}^{-1} \mathrm{ww}\right.$ ) and octopus (8.00 $\left.\mu \mathrm{g} \mathrm{g}^{-1} \mathrm{ww}\right)$ revealed the highest levels of $\mathrm{Cu}$, whereas hake showed the lowest levels $\left(0.08 \mu \mathrm{g} \mathrm{g}^{-1} \mathrm{ww}\right)$. Levels of $\mathrm{Mn}$ ranged between $0.13 \mu \mathrm{g} \mathrm{g}^{-1}$ ww (monkfish) and $2.82 \mu \mathrm{g} \mathrm{g}^{-1} \mathrm{ww}$ (mussel). Highest levels of Sr were detected in the old (154 $\left.\mu \mathrm{g} \mathrm{g}^{-1} \mathrm{ww}\right)$ and new (222 $\left.\mu \mathrm{g} \mathrm{g}^{-1} \mathrm{ww}\right)$ seaweed leafs, whereas the lowest levels were found in monkfish $\left(0.22 \mu \mathrm{g} \mathrm{g}^{-1} \mathrm{ww}\right)$, (Fig. 1, Supplementary Table S3). A similar 
trend was found for I, with the new seaweed leafs showing the highest concentration (433 $\left.\mu \mathrm{g} \mathrm{g}^{-1} \mathrm{ww}\right)$, whereas hake revealed the lowest I content $\left(0.12 \mu \mathrm{g} \mathrm{g}^{-1} \mathrm{ww}\right)$, (Fig. 1, Supplementary Table 3). As observed in Fig.1, mussel (84.9 $\left.\mu \mathrm{g} \mathrm{g}^{-1} \mathrm{ww}\right)$ showed the highest Fe levels among all raw seafood species, whereas hake showed the lowest Fe levels (Supplementary Table S3). 
A

Mercury

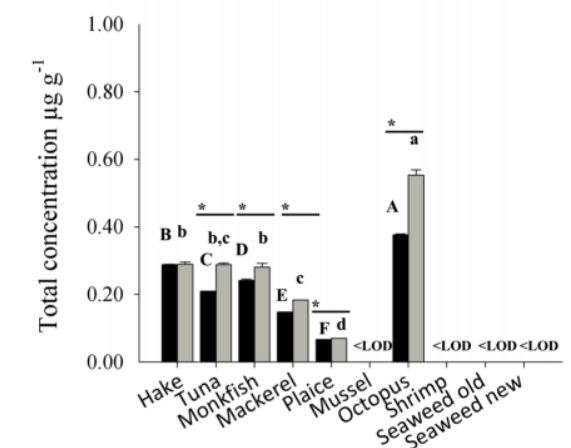

D

Cadmium

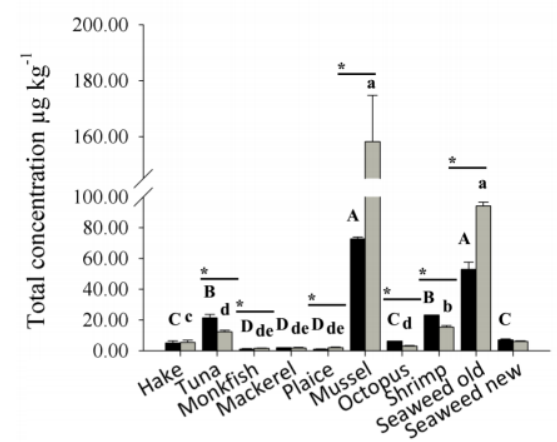

G

Copper

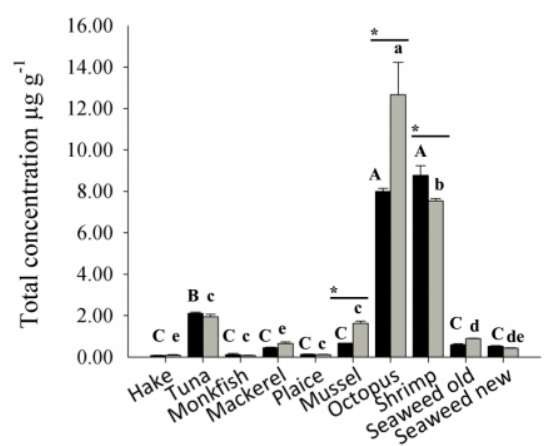

J

Iodine

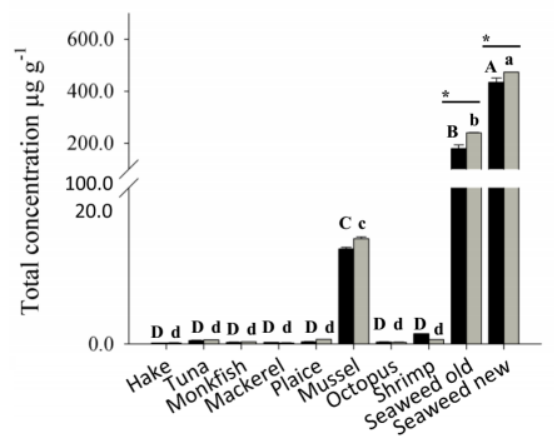

B

Methylmercury

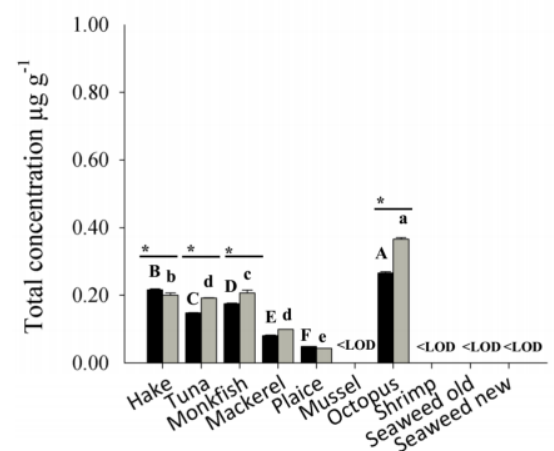

E

Zinc

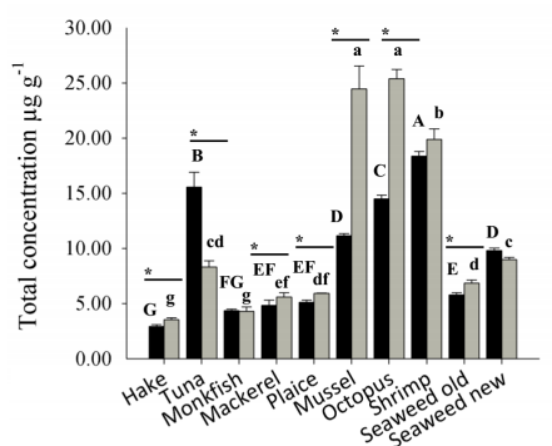

$\mathrm{H}$

Manganese

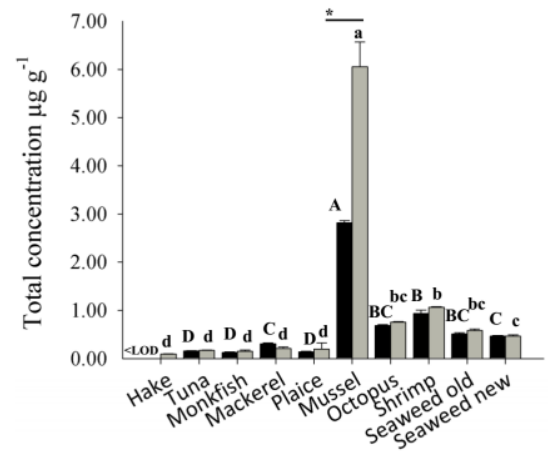

K

Iron

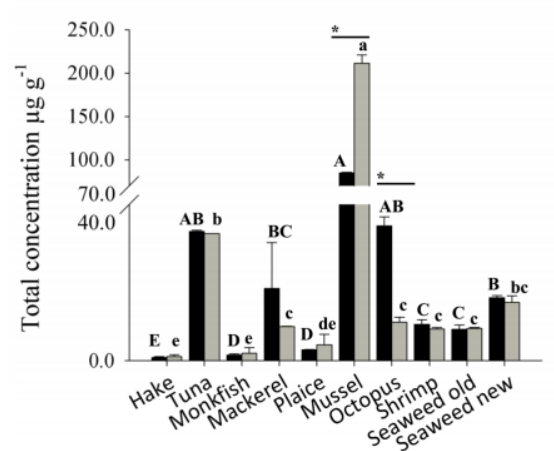

C
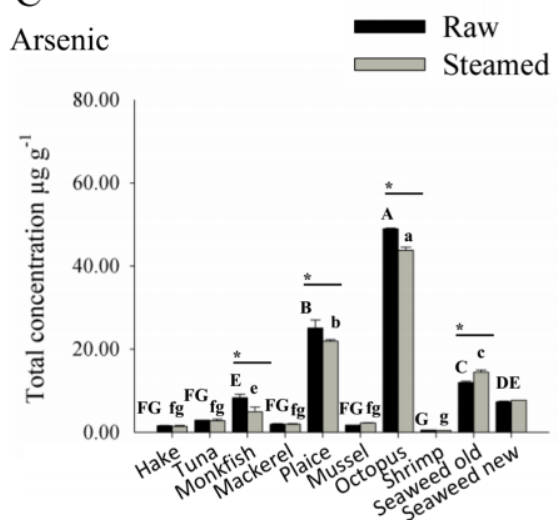

F

Selenium

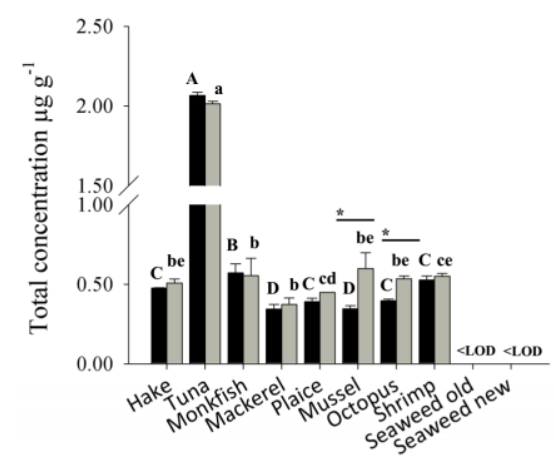

I

Strontium

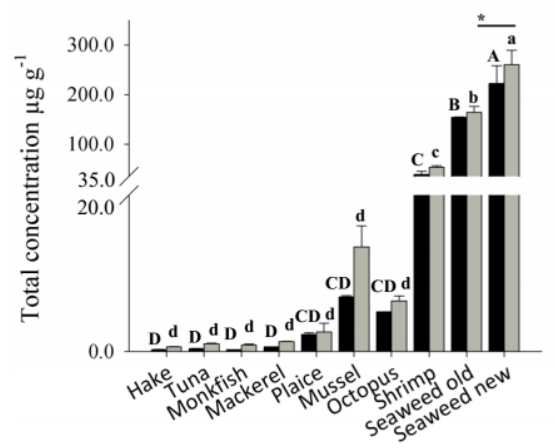


Fig. 1 - Concentrations of toxic (A - mercury, B - methylmercury, C - arsenic, D cadmium) and essential (E -zinc, F - selenium, G - copper, H - manganese, I - strontium, $\mathrm{J}$ - iodine and $\mathrm{K}$ - iron) elements in raw and steamed samples prior to in vitro digestion ( $\mu \mathrm{g} \mathrm{g}^{-1} \mathrm{ww}$ or $\mu \mathrm{g} \mathrm{kg}^{-1} \mathrm{ww}$, average \pm standard deviation). Different upper case letters indicate significantly differences between species for each element in raw seafood $(\mathrm{p}<$ 0.05); different lower case letters (a-g) indicate significantly differences between species for each element in steamed seafood $(\mathrm{p}<0.05) ; *$ represent differences between raw and steamed for each seafood species $(\mathrm{p}<0.05)$, please see detailed information in Supplementary tables 2 and 3 .

\subsection{Elements in steamed seafood}

Steaming led to an increase in $\mathrm{Hg}$ and $\mathrm{MeHg}$ concentrations, except in hake. For example, $\mathrm{Hg}$ and $\mathrm{MeHg}$ significantly increased approximately 30\% after steaming in tuna and octopus $(\mathrm{p}<0.05)$. In mackerel and monkfish, the increase was around $20 \%$ (p < 0.05), (Fig. 1, Supplementary Table S2). Arsenic content in monkfish, plaice and octopus was significantly lower after steaming compared with the raw product $(\mathrm{p}<$ 0.001). The As content in the remaining species was not significantly affected by steaming (Fig. 1). Steaming induced statistically higher levels of $\mathrm{Cd}$ in mussel, plaice and in the old part of seaweed $(\mathrm{p}<0.05)$. In contrast, tuna, monkfish, shrimp and octopus levels of $\mathrm{Cd}$ were significantly lower in steamed products $(\mathrm{p}<0.05)$, whereas no differences were observed between raw and steamed hake, mackerel and the newer seaweed segment (Fig. 1, Supplementary Table S2).

$\mathrm{Zn}$ content increased significantly after steaming in hake, mackerel, plaice, octopus, mussel, shrimp and old seaweed leafs (Fig. 1, p < 0.05). In general no 
significant differences were detected in Se between raw and steamed samples ( $p$ > 0.05), except in octopus and mussels. Octopus and mussels were the only species revealing a significant increase in $\mathrm{Cu}$ concentration after steaming (Fig. 1, Supplementary Table S3, p < 0.05). After steaming, mussel was the only species revealing significant changes in Mn levels, increasing to $6.06 \mu \mathrm{g} \mathrm{g}^{-1}(\mathrm{p}<0.05)$. Once steamed, only the new seaweed revealed a significant increase in Sr concentration reaching $260 \mu \mathrm{g} \mathrm{g}^{-1} \mathrm{ww}$ (Supplementary Table S3). Steaming resulted in a significant increase of I concentration only in the old and newer parts of the seaweeds $(p<0.05)$. Steaming only significantly affected Fe levels in mussel (increasing to $211 \mu \mathrm{g} \mathrm{g}^{-1} \mathrm{ww}$ ) and octopus (decreasing to $9.85 \mu^{g^{-1}}{ }^{-1}$ w) (Fig. 1, Supplementary Table S3).

\section{$\underline{\text { 3.3. Bioaccessibility of elements }}$}

\subsubsection{Bioaccessibility of proteins}

In general, high protein digestibility was observed in both raw and steamed samples from all commercial species analysed, ranging from $61.0 \%$ (steamed mussel) and $98.9 \%$ (raw octopus) (Supplementary Table S4). Seaweed showed the lowest protein bioaccessibility (raw $15.2 \%$; steamed $8.8 \%$ )

\subsubsection{Seafood species}

$\mathrm{Hg}$ bioaccessibility ranged between $61 \%$ (hake) and $11 \%$ (octopus), with most species presenting a bioaccessibility below $50 \%$ (Fig. 2, Supplementary Table S5). Hg recovery after the digestion process ranged between $70 \%$ in monkfish and $95 \%$ in 
octopus. Regarding $\mathrm{MeHg}$, the highest concentrations in the bioaccessible fractions were found in hake and monkfish, whereas the lowest $\mathrm{MeHg}$ bioaccessibility was observed in octopus $(10 \%, \mathrm{p}<0.05)$ (Fig. 2). In general, As bioaccessibility was high in all analysed species, ranging between $54 \%$ (seaweeds) and $98.3 \%$ (monkfish and octopus). Cd bioaccessibility was high for mussel (102 $\pm 10 \%)$ and shrimp (75 $\pm 7 \%)$, and low for tuna $(41 \pm 6 \%)$ (Fig. 2, Supplementary Table S5).

Zn bioaccessibility ranged between $28 \%$ (tuna) and $77 \%$ (old seaweed). Bioaccessible $\mathrm{Zn}$ values for mackerel and monkfish could not be determined as the results were below the limit of detection (Fig. 2, Supplementary Table S6). The bioaccessibility of Se was always higher than $59 \%$, showing low variability between seafood species. The highest Se bioaccessibility was observed in shrimp (97\%). Fig. 2 reveals that $\mathrm{Cu}$ bioaccessibility ranged between $44 \%$ (newer seaweed leafs) and $94 \%$ (octopus). This high variability in bioaccessibility among species was also observed for manganese, with shrimp showing the lowest Mn bioaccessibility (24\%). In octopus, Mn was $100 \%$ bioaccessible (Fig. 2, Supplementary Table S6). The bioaccessibility of both elements was statistically higher in the newer part of the seaweed $(\mathrm{p}<0.05)$. Sr bioaccessibility was highly variable between species and ranged between $18 \%$ (newer seaweed leafs) and $96 \%$ (mussel). In general, fish $\mathrm{Sr}$ bioaccessible values were below the LOQ. High I bioaccessibility was obtained for octopus (86\%), mussel (84\%) and the newer seaweed leafs ( $73 \%$ ), whereas only $46 \%$ of I was bioaccessible in tuna. Almost all Fe bioaccessible concentrations were below the limit of quantification, except for mussel (26\%) and tuna (69\%) respectively (Fig. 2, Supplementary Table S6). 
A

Mercury

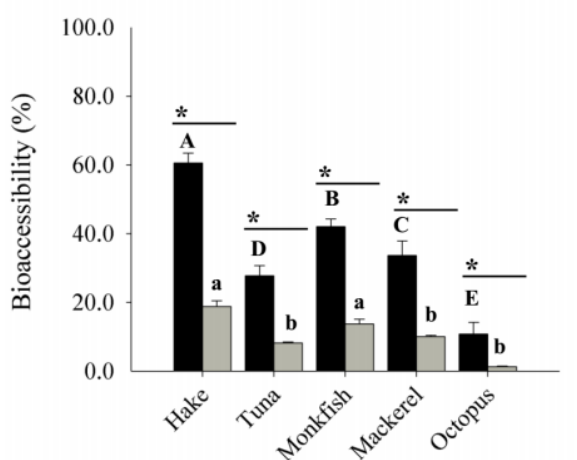

D

Cadmium

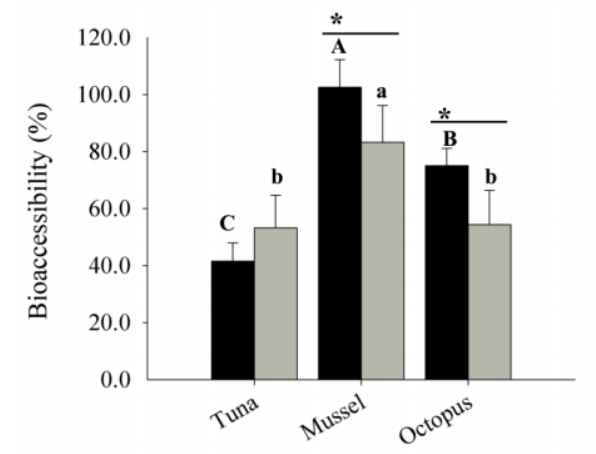

G

Copper

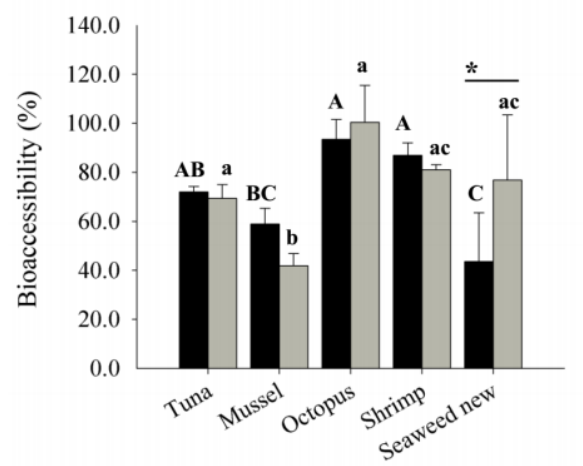

$\mathrm{J}$

Iodine

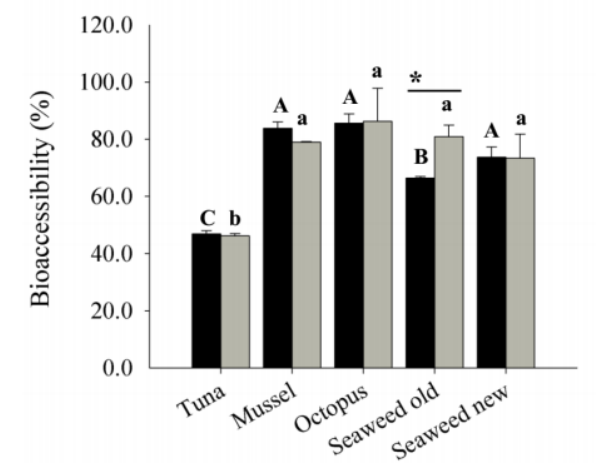

B

Methylmercury

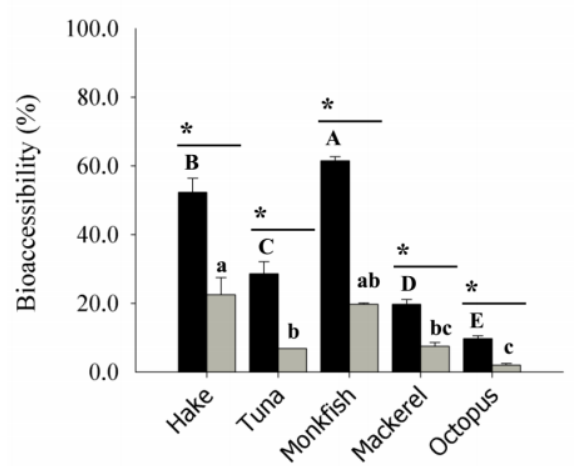

E

Zinc

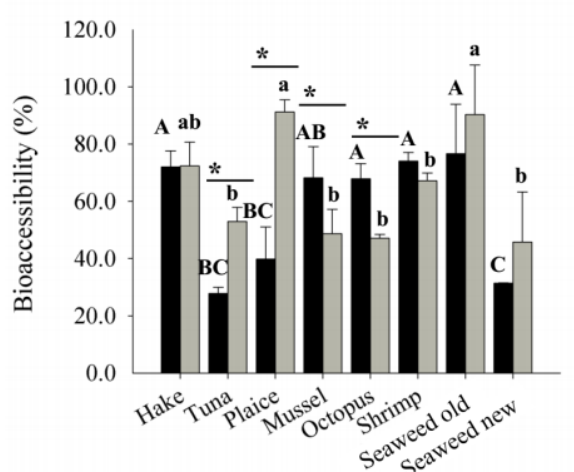

$\mathrm{H}$

Manganese

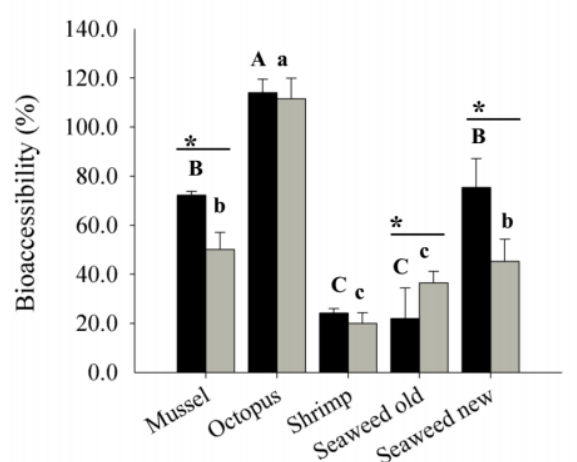

K

Iron

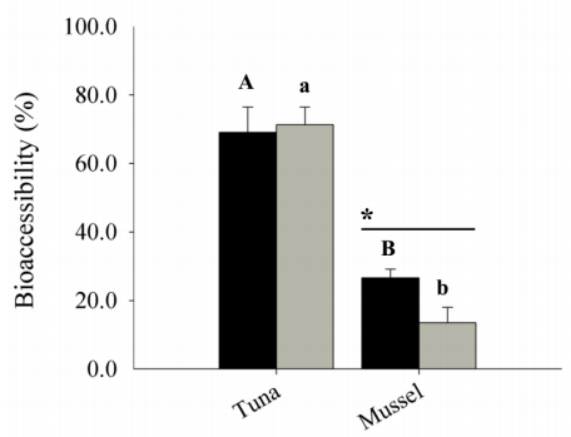

C

Arsenic

Raw

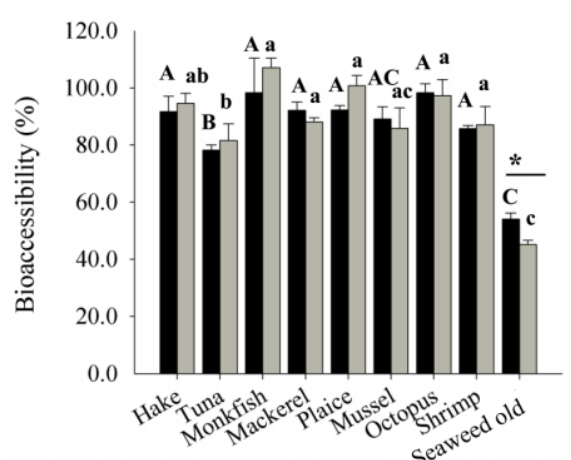

F

Selenium

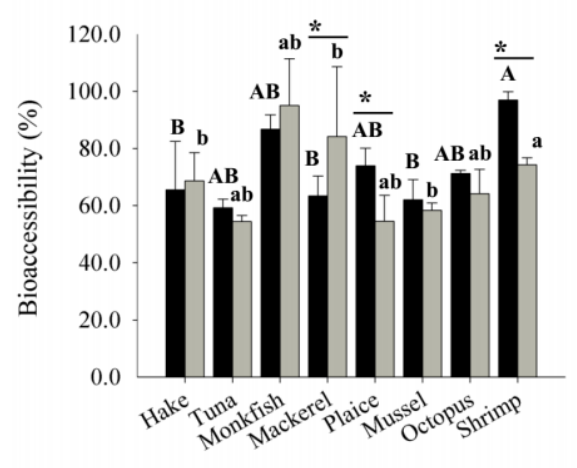

I

Strontium

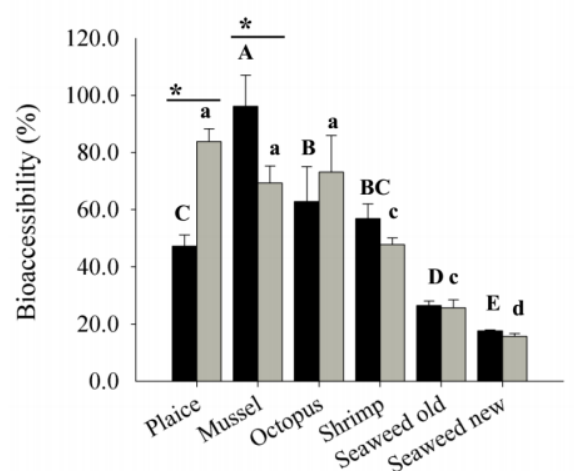


Fig. 2 -Bioaccessibility (\%) of toxic (A - mercury, B - methylmercury, C - arsenic, D cadmium) and essential (E -zinc, F - selenium, G - copper, H - manganese, I - strontium, $\mathrm{J}$ - iodine and $\mathrm{K}$ - iron) elements in raw and steamed samples (average \pm standard deviation). Different upper case letters indicate significantly differences between species for each element in raw seafood $(\mathrm{p}<0.05)$; different lower case letters $(\mathrm{a}-\mathrm{g})$ indicate significantly differences between species for each element in steamed seafood $(\mathrm{p}<0.05) ; *$ represent differences between raw and steamed for each seafood species $(\mathrm{p}$ $<0.05)$, please see detailed information in Supplementary tables 5 and 6.

\subsubsection{Effect of steaming}

For all analysed species, steaming significantly decreased total $\mathrm{Hg}$ bioaccessibility ( $\mathrm{p}<0.001$ ), ranging between $1 \%$ (octopus) and $19 \%$ (hake). Additionally, $\mathrm{MeHg}$ bioaccessibility also significantly decreased in all species after steaming $(\mathrm{p}<0.001)$. MeHg bioaccessibility varied between $2.1 \%$ (octopus) and 22.5 $\%$ (hake) in steamed seafood (Fig. 2, Supplementary Table S5). No statistical differences were registered in the bioaccessibility of As in raw and steamed seafood (Supplementary table 5). In contrast, Cd bioaccessibility decreased around $20 \%$ in mussel and shrimp after steaming ( $\mathrm{p}$ < 0.05) (Fig. 2, Supplementary Table S5).

In fish (tuna and plaice), Zn bioaccessibility increased after steaming $(\mathrm{p}<0.05)$, whereas $\mathrm{Zn}$ bioaccessibility decreased in molluscs after the culinary treatment. Se bioaccessibility decreased after steaming in shrimp (74\%) and plaice (54\%), whereas for mackerel, Se bioaccessibility increased after steaming $(84 \%)(\mathrm{p}<0.05)$. No significant differences were found between raw and steamed bioaccessible Se in hake, tuna, monkfish, octopus and mussel ( $\mathrm{p}>0.05)$ (Fig. 2). In the newer seaweed leafs, 
steaming increased and decreased $\mathrm{Cu}$ and $\mathrm{Mn}$, respectively (Fig. 2, Supplementary Table S6). In contrast, the culinary treatment did not significantly change $\mathrm{Cu}$ bioaccessibility in octopus, mussel and shrimp ( $\mathrm{p}>0.05)$. Concerning $\mathrm{Sr}$ bioaccessibility, only plaice (increased $-84 \%$ ) and mussel (decreased $-69 \%$ ) revealed statistically changes after the culinary treatment $(\mathrm{p}<0.05)$. Steaming only significantly affected I bioaccessibility in the older seaweed part (66\% - raw, $81 \%$ - steamed) (p < 0.05). Fe bioaccessibility only decreased after steaming in mussel ( $\mathrm{p}<0.05$ ) (Fig. 2, Supplementary Table S6).

Analysis of correlations between total element concentration $\left(\mathrm{mg} \mathrm{kg}^{-1} \mathrm{ww}\right.$ or $\mu \mathrm{g}$ $\mathrm{kg}^{-1} \mathrm{ww}$ ) and bioaccessibility (\%) in raw and steamed seafood are shown in Table 3. For almost all elements, no correlation was observed between elements concentration and bioaccessibility $(\mathrm{p}>0.05)$. The exceptions were $\mathrm{Cd}$ and $\mathrm{Zn}$, where bioaccessibility was positively correlated with the total elemental concentration $(\mathrm{Cd}, \mathrm{r}=1.000$ in steamed, $\mathrm{p}$ $<0.01 ; \mathrm{Cu}, \mathrm{r}=0.895$ in raw, $\mathrm{p}<0.05)$. In contrast, $\mathrm{Sr}$ was negatively correlated in raw and steamed samples (raw r $=0.811, \mathrm{p}<0.05$; steamed $\mathrm{r}=0.950, \mathrm{p}<0.01$ ) (Table 3).

\section{Table 3.}

Correlation coefficient between element concentration ( $\mathrm{mg} / \mathrm{kg} \mathrm{w} . \mathrm{w}$ or $\mu \mathrm{g} / \mathrm{kg} \mathrm{w} . \mathrm{w})$ and bioaccessibility (\%) in raw and steamed seafood.

\begin{tabular}{ccc} 
& Raw & Steamed \\
\hline Hg & 0.491 & 0.661 \\
$\mathbf{M e H g}$ & 0.1 & 0.327 \\
$\mathbf{A s}$ & 0.0451 & 0.0047 \\
$\mathbf{C d}$ & 0.853 & $1.000 * * \uparrow$ \\
$\mathbf{Z n}$ & 0.0741 & 0.575 \\
$\mathbf{S e}$ & 0.298 & 0.422 \\
$\mathbf{C u}$ & $0.895^{*} \uparrow$ & 0.751 \\
$\mathbf{M n}$ & 0.114 & 0.0563 \\
$\mathbf{S r}$ & $0.811 * \downarrow$ & $0.950 * * \downarrow$ \\
$\mathbf{I}$ & 0.0663 & 0.0771 \\
$\mathbf{F e}$ & $\mathrm{n.d}$ & 0.0384 \\
Statistical significance: ${ }^{*} \mathrm{p}<0.05 ; * \mathrm{p}<0.01 ; \downarrow$ negative correlation and $\uparrow$ positive
\end{tabular}




\subsection{Impact on toxic elements exposure in seafood}

\subsubsection{Se-dependant benefits}

Before digestion, Se:Hg or Se:MeHg molar ratios were higher than 1 in all raw and steamed seafood. The highest $\mathrm{Se}: \mathrm{Hg}$ and Se:MeHg were observed in tuna, while the lowest occurred in octopus $(\mathrm{p}<0.05)$. Before digestion, steaming only led to a significant increase in Se: $\mathrm{MeHg}$ for hake, whereas significant decrease in Se:Hg was observed for hake, tuna, monkfish and mackerel, as well as in Se:MeHg for tuna and monkfish (Table 4). In the bioaccessible samples, tuna and octopus showed the highest Se:Hg and Se:MeHg ratios ( $<$ 0.05), and in both species Se:Hg and Se:MeHg ratios increased after steaming $(\mathrm{p}<0.01$, Table 4). Steaming induced statistical increased Se:Hg and Se:MeHg ratios in the bioaccessible fraction of tuna, mackerel and octopus (Table 4).

Few significant differences were observed in $\mathrm{HBV}_{\mathrm{Se}}$ values in relation to $\mathrm{Hg}$ and MeHg. Before digestion, as well, in bioaccessible samples the highest $\mathrm{HBV}_{\mathrm{Se}}$ values were observed in tuna $(\mathrm{p}<0.05)$. In bioaccessible samples, $\mathrm{HBV}_{\mathrm{Se}}($ for $\mathrm{Hg}$ and $\mathrm{MeHg}$ ) values were not significant different in hake, mackerel and octopus ( $p>0.05$, Table 4). The culinary treatment only affected $\mathrm{HBV}_{\mathrm{Se}}$ before digestion in tuna and octopus $(\mathrm{p}<$ 0.05 ; increasing in octopus and decreasing in tuna), whereas no effects of steaming were observed in bioaccessible samples (Table 4). 
Table 4.

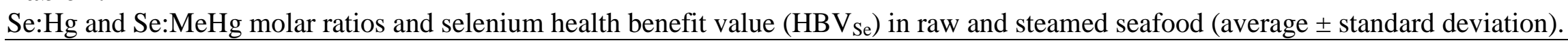

\begin{tabular}{|c|c|c|c|c|c|c|c|c|c|}
\hline & & \multicolumn{2}{|c|}{ Se:Hg } & \multicolumn{2}{|c|}{ Se:MeHg } & \multicolumn{2}{|c|}{$\mathrm{HBV}_{\mathrm{Se}}$ for $\mathrm{Hg}$} & \multicolumn{2}{|c|}{$\mathrm{HBV}_{\mathrm{Se}}$ for $\mathrm{MeHg}$} \\
\hline & & BD $^{1}$ & BIO $^{2}$ & BD & BIO & BD & BIO & BD & BIO \\
\hline \multirow{2}{*}{ Hake } & Raw & $4.93 \pm 0.00 \mathrm{~b}$ & $5.92 \pm 0.64 \mathrm{~b}$ & $6.00 \pm 0.00 \mathrm{c}$ & $7.45 \pm 1.02 \mathrm{~b}$ & $5.77 \pm 0.00 \mathrm{c}$ & $3.81 \pm 0.72 b c$ & $5.88 \pm 0.00 \mathrm{c}$ & $3.86 \pm 0.72 b c$ \\
\hline & Steamed & $4.54 \pm 0.00 \mathrm{~B}$ & $17.52 \pm 1.27 \mathrm{C}$ & $6.91 \pm 0.00 \mathrm{C}$ & $21.47 \pm 3.67 \mathrm{C}$ & $5.97 \pm 0.00 \mathrm{~B}$ & $4.40 \pm 0.63 \mathrm{~B}$ & $6.18 \pm 0.07 \mathrm{~B}$ & $4.40 \pm 0.63 \mathrm{~B}$ \\
\hline \multirow{2}{*}{ Tuna } & Raw & $24.23 \pm 0.03 \mathrm{a}$ & $63.71 \pm 5.35 \mathrm{a}$ & $38.13 \pm 0.00 \mathrm{a}$ & $79.62 \pm 6.68 \mathrm{a}$ & $26.62 \pm 1.00 \mathrm{a}$ & $15.50 \pm 0.77 \mathrm{a}$ & $26.65 \pm 1.00 \mathrm{a}$ & $15.50 \pm 0.77 \mathrm{a}$ \\
\hline & Steamed & $21.44 \pm 0.01 \mathrm{~A}$ & $195.25 \pm 46.97 \mathrm{~A}$ & $28.70 \pm 0.00 \mathrm{~A}$ & $235.08 \pm 41.63 \mathrm{~A}$ & $25.44 \pm 0.95 \mathrm{~A}$ & $15.35 \pm 2.58 \mathrm{~A}$ & $25.47 \pm 0.95 \mathrm{~A}$ & $15.35 \pm 2.58 \mathrm{~A}$ \\
\hline \multirow{2}{*}{ Monkfish } & Raw & $3.95 \pm 0.25 c$ & $10.65 \pm 1.52 \mathrm{~b}$ & $8.91 \pm 0.00 \mathrm{~b}$ & $13.73 \pm 2.07 \mathrm{~b}$ & $6.93 \pm 0.29 b$ & $6.78 \pm 1.04 \mathrm{~b}$ & $7.37 \pm 0.28 b$ & $6.81 \pm 1.03 b$ \\
\hline & Steamed & $3.18 \pm 0.01 \mathrm{C}$ & $25.36 \pm 5.59 \mathrm{C}$ & $7.30 \pm 0.00 \mathrm{~B}$ & $31.42 \pm 8.28 \mathrm{CD}$ & $6.18 \pm 0.18 \mathrm{~B}$ & $5.94 \pm 1.48 \mathrm{~B}$ & $6.82 \pm 0.20 \mathrm{~B}$ & $5.94 \pm 1.48 \mathrm{~B}$ \\
\hline \multirow{2}{*}{ Mackerel } & Raw & $4.79 \pm 0.36 b$ & $14.30 \pm 1.31 \mathrm{~b}$ & $5.87 \pm 0.44 c$ & $18.84 \pm 1.90 \mathrm{~b}$ & $4.26 \pm 0.20 \mathrm{~d}$ & $2.73 \pm 0.100 \mathrm{c}$ & $4.36 \pm 0.19 \mathrm{~d}$ & $2.73 \pm 0.10 \mathrm{c}$ \\
\hline & Steamed & $4.43 \pm 0.00 \mathrm{~B}$ & $53.14 \pm 7.85 \mathrm{C}$ & $5.90 \pm 0.00 \mathrm{D}$ & $68.52 \pm 29.18 \mathrm{BD}$ & $4.32 \pm 0.02 \mathrm{C}$ & $3.97 \pm 1.15 \mathrm{~B}$ & $4.45 \pm 0.02 \mathrm{C}$ & $3.97 \pm 3.97 \mathrm{~B}$ \\
\hline \multirow{2}{*}{ Octopus } & Raw & $2.67 \pm 0.00 \mathrm{~d}$ & $25.67 \pm 3.63 \mathrm{ab}$ & $4.05 \pm 0.00 \mathrm{~d}$ & $28.30 \pm 0.28 \mathrm{ab}$ & $3.09 \pm 0.13 \mathrm{e}$ & $4.31 \pm 1.30 \mathrm{bc}$ & $3.49 \pm 0.14 d$ & $4.31 \pm 1.30 \mathrm{bc}$ \\
\hline & Steamed & $2.45 \pm 0.00 \mathrm{D}$ & $118.82 \pm 10.8 \mathrm{~B}$ & $3.98 \pm 0.00 \mathrm{E}$ & $109.80 \pm 29.85 \mathrm{~B}$ & $4.06 \pm 0.01 \mathrm{C}$ & $4.34 \pm 0.57 \mathrm{~B}$ & $4.75 \pm 0.01 \mathrm{C}$ & $4.34 \pm 0.57 \mathrm{~B}$ \\
\hline
\end{tabular}

${ }^{1} \mathrm{BD}$ - before digestion; ${ }^{2} \mathrm{BIO}$ - bioaccessible element

Different lower case letters (a-d) in each column indicate significantly differences between species in raw seafood ( $p<0.05)$

Different upper case letters (A-D) in each column indicate significantly differences between species in steamed seafood ( $p<0.05)$

Values highlighted in light gray represent differences between raw and steamed for each seafood species $(\mathrm{p}<0.05)$

$\mathrm{n}=25$ for fish and cephalopods species; $\mathrm{n}=20$ for seaweed; $\mathrm{n}=50$ for bivalves and crustaceans 


\subsubsection{Benefit-Risk balance}

Table 5 shows the benefit-risk balance for the consumption of seafood species (raw and cooked) based on RDAs and ULs set for each essential element. Percentages of RDAs and ULs for a consumption of $150 \mathrm{~g}$ seafood varied according to species and element. Crustaceans and cephalopods revealed high \% RDAs for Zn (between 19 and $35 \%$ ) and $\mathrm{Cu}$ (over $100 \%$ ), whereas remarkably higher Se intakes were observed in fish species, particularly tuna (over $100 \%$ of RDA and $65 \%$ of UL). Mussels revealed the highest \% AL and \% RDA of Mn and Fe, respectively, especially after steaming $(\mathrm{Mn}=39.5 \%$ and $\mathrm{Fe}>100 \%)$. Mussels and macroalgae also provided over $100 \%$ of RDA set for I. In what concerns toxic elements, the consumption of $150 \mathrm{~g}$ octopus revealed the highest intake of $\mathrm{MeHg}$ (44\% and $60 \%$ of TWI in raw and cooked samples, respectively), whereas the highest Cd \% TWI was registered with mussels (Table 6). 
Table 5.

Percentage of the recommended dietary allowances (RDA)of each element considering the consumption of a portion size of $150 \mathrm{~g}$ of fish, mollusks and crustaceans, or $50 \mathrm{~g}$ of seaweed. In some cases action limits (AL) and upper limits (UL) are taken into account and / or specified (see note at the bottom of the table for more details).

\begin{tabular}{|c|c|c|c|c|c|c|c|c|c|c|c|c|}
\hline & \multicolumn{2}{|c|}{$\mathbf{Z n}^{1}$} & \multicolumn{2}{|c|}{$\mathrm{Zn}^{2}$} & \multicolumn{2}{|c|}{$\mathrm{Se}^{1}$} & \multicolumn{2}{|c|}{$\mathrm{Se}^{2}$} & \multicolumn{2}{|c|}{$\mathrm{Cu}^{1}$} & \multicolumn{2}{|c|}{$\mathrm{Cu}^{2}$} \\
\hline & Raw & Steamed & Raw & Steamed & Raw & Steamed & Raw & Steamed & Raw & Steamed & Raw & Steamed \\
\hline Hake & 4.0 & 4.8 & 2.8 & 3.5 & $\begin{array}{c}>\text { RDA } \\
(3.9)\end{array}$ & $\begin{array}{c}>\text { RDA } \\
(5.3)\end{array}$ & 84.0 & 94.9 & 1.3 & 1.6 & 0.0 & 0.0 \\
\hline Tuna & 20.5 & 11.3 & 5.7 & 6.0 & $\begin{array}{c}>\text { RDA } \\
(65.0)\end{array}$ & $\begin{array}{l}>\text { RDA } \\
(61.8)\end{array}$ & $\begin{array}{c}>\text { RDA } \\
(32.9)\end{array}$ & $\begin{array}{c}>\text { RDA } \\
(27.3)\end{array}$ & 35.3 & 32.5 & 25.4 & 22.6 \\
\hline Mackerel & 6.5 & 7.6 & 0.0 & 0.0 & 92.7 & $\begin{array}{c}>\text { RDA } \\
(0.2)\end{array}$ & 58.8 & 85.4 & 7.4 & 1.1 & 0.0 & 0.0 \\
\hline Plaice & 7.0 & 8.1 & 2.8 & 7.4 & $\begin{array}{c}\text { > RDA } \\
(0.9)\end{array}$ & $\begin{array}{c}>\text { RDA } \\
(3.1)\end{array}$ & 78.7 & 66.6 & 2.4 & 2.1 & 0.0 & 0.0 \\
\hline Octopus & 19.1 & 34.6 & 13.0 & 16.3 & $\begin{array}{c}>\text { RDA } \\
(1.3)\end{array}$ & $\begin{array}{c}>\text { RDA } \\
(6.3)\end{array}$ & 77.7 & 93.5 & $\begin{array}{c}>\text { RDA } \\
(3.0)\end{array}$ & $\begin{array}{c}>\text { RDA } \\
(10.0)\end{array}$ & $\begin{array}{c}>\text { RDA } \\
(2.2)\end{array}$ & $\begin{array}{c}>\text { RDA } \\
(10.1)\end{array}$ \\
\hline Mussel & 15.0 & 33.3 & 10.2 & 16.2 & 95.5 & $\begin{array}{c}>\text { RDA } \\
(8.7)\end{array}$ & 59.3 & 95.3 & 11.3 & 27.2 & 6.7 & 11.4 \\
\hline Seaweed new & 4.5 & 4.1 & 1.4 & 1.9 & 0.0 & 0.0 & 0.0 & 0.0 & 2.9 & 2.4 & 1.3 & 1.8 \\
\hline
\end{tabular}


Table5 cont

\begin{tabular}{|c|c|c|c|c|c|c|c|c|c|c|c|c|}
\hline & \multicolumn{2}{|c|}{$\mathrm{Mn}^{1}$} & \multicolumn{2}{|c|}{$\mathbf{M n}^{2}$} & \multicolumn{2}{|c|}{$\mathbf{I}^{1}$} & \multicolumn{2}{|r|}{$I^{2}$} & \multicolumn{2}{|c|}{$\mathrm{Fe}^{1}$} & \multicolumn{2}{|c|}{$\mathrm{Fe}^{2}$} \\
\hline & Raw & Steamed & Raw & Steamed & Raw & Steamed & Raw & Steamed & Raw & Steamed & Raw & Steamed \\
\hline Hake & $0.0^{*}$ & $0.6^{*}$ & $0.0^{*}$ & $0.0^{*}$ & 12.0 & 13.8 & 0.0 & 0.0 & 0.6 & 1.0 & 0.0 & 0.0 \\
\hline Tuna & $1.0^{*}$ & $1.1^{*}$ & $0.0^{*}$ & $0.0^{*}$ & 44.2 & 51.7 & 20.7 & 23.9 & 27.5 & 27.1 & 19.0 & 19.3 \\
\hline Mackerel & $2.0^{*}$ & $1.4^{*}$ & $0.0^{*}$ & $0.0^{*}$ & 18.1 & 13.9 & 0.0 & 0.0 & 8.5 & 7.3 & 0.0 & 0.0 \\
\hline Monkfish & $0.8^{*}$ & $1.0^{*}$ & $0.0^{*}$ & $0.0^{*}$ & 20.3 & 26.7 & 0.0 & 0.0 & 1.2 & 2.4 & 0.0 & 0.0 \\
\hline Plaice & $0.9 *$ & $1.3^{*}$ & $0.0^{*}$ & $0.0^{*}$ & 28.2 & 58.3 & 0.0 & 0.0 & 2.3 & 3.4 & 0.0 & 0.0 \\
\hline Octopus & 4.4* & 4.9* & $5.0 *$ & $5.5^{*}$ & 22.9 & 21.4 & 19.6 & 18.5 & 28.8 & 8.2 & 0.0 & 0.0 \\
\hline Mussel & $18.4 *$ & 39.5* & $13.3 *$ & $19.8 *$ & $\begin{array}{l}>\text { RDA } \\
(>\mathrm{UL})\end{array}$ & $\begin{array}{l}>\text { RDA } \\
(>\mathrm{UL})\end{array}$ & $\begin{array}{l}>\text { RDA } \\
(>\mathrm{UL})\end{array}$ & $\begin{array}{l}>\text { RDA } \\
(>\mathrm{UL})\end{array}$ & 70.7 & $\begin{array}{l}>\text { RDA } \\
(30.4)\end{array}$ & 18.8 & 23.8 \\
\hline Shrimp & 6.1* & $6.9 *$ & $1.5^{*}$ & $1.4^{*}$ & $\begin{array}{c}>\text { RDA } \\
(4.4)\end{array}$ & 54.9 & 0.0 & 0.0 & 7.8 & 6.8 & 0.0 & 0.0 \\
\hline Seaweed old & $1.1^{*}$ & $1.3^{*}$ & $0.2^{*}$ & $0.5^{*}$ & $\begin{array}{l}>\mathrm{RDA} \\
(>\mathrm{UL})\end{array}$ & $\begin{array}{l}>\text { RDA } \\
(>\mathrm{UL})\end{array}$ & $\begin{array}{l}>\text { RDA } \\
(>\mathrm{UL})\end{array}$ & $\begin{array}{l}>\mathrm{RDA} \\
(>\mathrm{UL})\end{array}$ & 2.2 & 2.3 & 0.0 & 0.0 \\
\hline Seaweed new & $1.0^{*}$ & $1.0^{*}$ & $0.8^{*}$ & $0.5^{*}$ & $\begin{array}{l}>\mathrm{RDA} \\
(>\mathrm{UL})\end{array}$ & $\begin{array}{l}>\mathrm{RDA} \\
(>\mathrm{UL})\end{array}$ & $\begin{array}{l}>\mathrm{RDA} \\
(>\mathrm{UL})\end{array}$ & $\begin{array}{l}>\mathrm{RDA} \\
(>\mathrm{UL})\end{array}$ & 4.5 & 4.1 & 0.0 & 0.0 \\
\hline
\end{tabular}

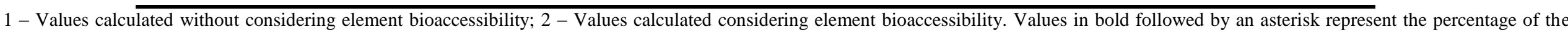

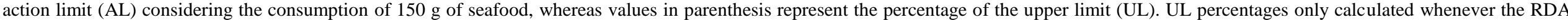

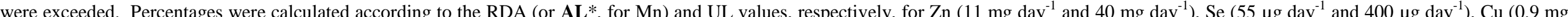

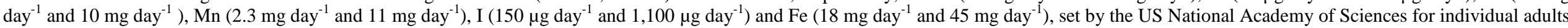
aged between 19 and 50 years (USNAS, 2010) 
In terms of cooking effect, no clear pattern was observed (Tables 5 and 6), as contents of some elements increased in some seafood species after steaming (e.g. Zn and Se, except in tuna and monkfish; MeHg, except in plaice), while in others contents drastically decreased (e.g. Fe in octopus). Despite some exceptions (i.e. $\mathrm{Cu}$ and $\mathrm{Mn}$ in octopus), overall, the inclusion of elements' bioaccessibility tended to decrease the percentages of both RDAs (and ULs) and TWIs for each element with the consumption of $150 \mathrm{~g}$ of seafood (Tables 5 and 6$)$.

Table 6.

Percentage of the tolerable weekly intakes (TWI) set for $\mathrm{MeHg}$ and $\mathrm{Cd}$, accomplished with the consumption of $150 \mathrm{~g}$ of fish, mollusks and crustaceans, or $50 \mathrm{~g}$ of seaweed.

\begin{tabular}{|c|c|c|c|c|c|c|c|c|}
\hline & \multicolumn{2}{|c|}{$\mathrm{MeHg}^{1}$} & \multicolumn{2}{|c|}{$\mathrm{MeHg}^{2}$} & \multicolumn{2}{|c|}{$\mathrm{Cd}^{1}$} & \multicolumn{2}{|c|}{$\mathrm{Cd}^{2}$} \\
\hline & Raw & Steamed & Raw & Steamed & Raw & Steamed & Raw & Steamed \\
\hline Hake & 35.6 & 33.1 & 18.6 & 7.5 & 0.4 & 0.5 & 0.0 & 0.0 \\
\hline Tuna & 24.4 & 31.6 & 7.0 & 2.2 & 1.8 & 1.1 & 0.8 & 0.6 \\
\hline Mackerel & 13.0 & 16.3 & 8.0 & 3.2 & 0.2 & 0.2 & 0.0 & 0.0 \\
\hline Monkfish & 28.8 & 34.1 & 5.7 & 2.6 & 0.1 & 0.1 & 0.0 & 0.0 \\
\hline Plaice & 8.1 & 7.1 & 0.0 & 0.0 & 0.1 & 0.2 & 0.0 & 0.0 \\
\hline Octopus & 43.8 & 60.3 & 4.3 & 1.2 & 0.5 & 0.3 & 0.0 & 0.0 \\
\hline Mussel & 0.0 & 0.0 & 0.0 & 0.0 & 6.2 & 13.6 & 6.4 & 11.3 \\
\hline Shrimp & 0.0 & 0.0 & 0.0 & 0.0 & 2.0 & 1.3 & 1.5 & 0.7 \\
\hline Seaweed old & 0.0 & 0.0 & 0.0 & 0.0 & 1.5 & 2.7 & 0.0 & 0.0 \\
\hline Seaweed new & 0.0 & 0.0 & 0.0 & 0.0 & 0.2 & 0.2 & 0.0 & 0.0 \\
\hline
\end{tabular}

\section{Discussion}

\subsection{Protein bioaccessibility - in vitro digestion efficiency}

Nutrients and contaminants available in seafood and their bioaccessibility have been studied during the last years to evaluate the risks and benefits associated with 
seafood consumption (Cardoso et al., 2015; He et al., 2010; Vazquez et al., 2015). The in vitro digestion procedure adapted from Versantvoort et al. (2005) and Minekus et al. (2014) optimized for different seafood matrices enabled a proper digestion of seafood samples, as the vast majority of proteins were hydrolysed and released to the bioaccessible fraction, in the range of reported values for the digestible fish proteins (77 to $99 \%$ ), (Usydus et al., 2009). In steamed samples, protein bioaccessibility decreased as expected due to the thermal treatment, and consequent protein denaturation and configuration changes (Afonso et al., 2015; Matos et al., 2015). The in vitro digestion protocol used in this study revealed lower protein bioaccessibility for seaweeds. Seaweeds have a complex carbohydrate matrix structure that is difficult to enable the access of proteins to digestive enzymes and thus to ensure a proper digestion.

\subsection{Toxic elements bioaccessible in seafood}

In the present study, analysis of total $\mathrm{Hg}$ (including $\mathrm{MeHg}$ ) in seafood revealed octopus as the species showing the highest concentration, and where $\mathrm{MeHg}$ concentrations increased after steaming. For example, steamed octopus $\left(0.553 \mu \mathrm{g} \mathrm{g}^{-1}\right.$ ww) showed levels higher than the maximum levels (MLs) set by EU. The effects of culinary treatments are relevant, as in general, they induce an increase in $\mathrm{Hg}$ as a result of water loss during steaming (Maulvault et al., 2011; Torres-Escribano et al., 2010). Nevertheless, $\mathrm{Hg}$ or $\mathrm{MeHg}$ concentrations do not always reflect the bioaccessible fraction that is released from seafood during the digestive process and potentially reaches the systemic circulation, and the results obtained in the current study support this statement. In fact, it has been reported that an overestimation of health risks for humans associated to $\mathrm{Hg}$ and $\mathrm{MeHg}$ is likely to occur (Cano-Sancho et al., 2015), and in 
this study, low $\mathrm{Hg}$ and $\mathrm{MeHg}$ bioaccessibility was observed supporting this statement. To our knowledge this is the first study reporting $\mathrm{Hg}$ and $\mathrm{MeHg}$ bioaccessibility in octopus, showing the lowest bioaccessibility $(\sim 11 \%)$. The high variability between species reported in literature may be due to different in vitro digestion protocols used, distinct nutritional composition of the food matrix, different $\mathrm{Hg} / \mathrm{MeHg}$ accumulation rates in seafood, seafood feeding habitats and other biotic parameters (Cabanero et al., 2004; Jadan-Piedra et al., 2016; Kwasniak et al., 2012; Siedlikowski et al., 2015; Torres-Escribano et al., 2010; Torres-Escribano et al., 2011).

In the case of As, octopus and plaice showed the highest concentrations, and this was not surprising as benthic species that live in direct contact with the sea bottom are more exposed to As contamination (Anacleto et al., 2009; Cano-Sancho et al., 2015). Both old and news seaweed leafs accumulated significant levels of As (7.30 - 12.0). The values obtained in the present study were lower than those reported for the same seaweed species in a previous study (Maehre et al., 2016), whereas for other seaweed species might contain higher As levels have been reported, such as the seaweed Laver, Porphyra abottae (33.0 $\mu \mathrm{g} \mathrm{g}^{-1} \mathrm{ww}$.). In a previous study, the culinary treatment (steaming, boiling) did not affect total As in Cancer pagurus muscle and brown meat (Maulvault et al., 2011), and similar results were observed in the current study for 6 species. Contrary to what was observed for $\mathrm{Hg}$, As bioaccessibility was high in almost all species,in accordance with previous findings (Laird and Chan, 2013; Laparra et al., 2007; Laparra et al., 2003; Maulvault et al., 2011; Peng et al., 2016). In fact, the low pH observed during the stomach digestion phase (gastric fluid) is responsible for the high As solubilisation (Oomen et al. 2003). Therefore, future studies should assess if the inorganic fraction of As (most toxic form) in seafood follows the same trend of total As. 
Mussel was the seafood species showing the highest $\mathrm{Cd}$ concentration, and populations where bivalves play a central role in the diet can be more exposed to toxicological effects associated with Cd (Amiard et al., 2008; Leufroy et al., 2012; Metian et al., 2009; Qin et al., 2015; Vandermeersch et al., 2015). High and low Cd contamination is associated to molluscs/algae and fish, respectively (Moreda-Pineiro et al., 2012). Levels of Cd in mussel, plaice and the older part of the seaweed increased after steaming. Similar findings were observed in steamed and boiled Cancer pagurus (Maulvault et al. 2011). Cadmium bioaccessibility was higher in mussel and octopus (shellfish) than in tuna, and similar findings were previously reported for mussel and shrimp (Leufroy et al., 2012). The same parameters that influenced $\mathrm{MeHg}$ bioaccessibility such as differences in moisture, food composition (proteins, fibres) and metal and cellular components interaction can explain the variability found in $\mathrm{Cd}$ bioaccessibility (Wang et al., 2014).

The influence of steaming in the toxic elements bioaccessibility provides more evidences concerning the accurate risks of seafood consumption. Indeed, steaming significantly reduced $\mathrm{Hg}$ and $\mathrm{MeHg}$ bioaccessibility in all seafood analysed. Similar findings have also been reported for other fish species (Afonso et al., 2015; CanoSancho et al., 2015; Maulvault et al., 2011; Torres-Escribano et al., 2011). Protein structure modification and loss of the native form by heating during culinary treatments can make the complexes $\mathrm{Hg}$-protein less accessible to digestive enzymes, and subsequently reduce their solubilisation during digestion. $\mathrm{MeHg}$ is bound to different proteins in the tissues, including albumin, glutathione or cysteine-rich proteins (Ouedraogo and Amyot, 2011). The reduction of $\mathrm{Cd}$ bioaccessibility observed in steamed mussel and octopus is in accordance with previous studies performed in shellfish, including mussels, oysters, clams and scallops (Gao and Wang, 2014; He and 
Wang, 2013; Metian et al., 2009). As observed for MeHg, the decrease in Cd bioaccessibility after steaming is likely due to the loss of highly digestible proteins during the steaming process (Amiard et al. 2008; Cabañero et al. 2004). Additionally, the formation of insoluble components due to the denaturation can reduce protein digestibility and subsequently decreases in Cd bioaccessibility (Kulp et al., 2003). In contrast to $\mathrm{MeHg}$ and $\mathrm{Cd}$, steaming has not affected As bioaccessibility (except seaweed), and is in agreement with previous studies in seafood subjected to different culinary treatments (Laparra et al., 2007; Laparra et al., 2003). Indeed, the amount of As bioaccessible was not correlated with the protein content of the seafood (Moreda-Piñero et al., 2012).

\subsection{Essential elements bioaccessible in seafood}

Shellfish (mussels, octopus and shrimp) are a good source of $\mathrm{Zn}, \mathrm{Mn}, \mathrm{Cu}$ and $\mathrm{Fe}$ in comparison to fish. Guérin et al. (2011). High Zn levels were also observed in mussels from Galicia (Spain), but shrimps and tuna from this region revealed low Zn values (Olmedo et al., 2013). Moreover, Cu concentrations were low compared to levels obtained in other studies (Leufroy et al. 2012, Guérin et al. 2011), but similar with those observed by Olmedo et al. (2013). In the present study, steaming generally increased Zn concentration in almost all seafood species, whereas $\mathrm{Cu}, \mathrm{Mn}$ and Fe levels only increased in mussel, octopus and shrimp. Excluding the low Mn and Fe bioaccessibility observed in shrimp and mussels, respectively, the bioaccessibility of these three essential elements in shellfish were always higher than $60 \%$. The high variability found in $\mathrm{Zn}$ bioaccessibility has already been observed in previous studies (He et al., 2015; Peng et al., 2016). Furthermore, previous findings also reported similar element ( $\mathrm{Zn}$, 
$\mathrm{Cu}, \mathrm{Mn}$ ) bioaccessibility in seafood (Amiard et al. 2008; Leufroy et al 2012; Metian et al. 2009, Peng et al., 2016). Additionally, the varying level of Mn bioaccessibility observed for shellfish in the current study has also been previously reported (He and Wang, 2013; Leufroy et al., 2012).

Se content revealed a great variability, as previously reported by Marval-Léon et al (2014), and Se levels were similar to the current study. Steaming increased significantly the Se content in octopus and mussels in accordance with previous findings reported for blue shark after grilling and steaming (Matos et al., 2015). The increase in Se content is likely related to water loss during culinary treatment (Afonso et al., 2015). Se bioaccessibility was high in all seafood species, and similar Se bioaccessibility has been reported for fish (Cabanero et al., 2004; Calatayud et al., 2012; Jadan-Piedra et al., 2016; Matos et al., 2015) and shellfish (Calatayud et al., 2012; Laird and Chan, 2013). These authors suggested that the gastrointestinal fluid composition and the food matrix composition, can explain the variation in essential elements bioaccessibility between species.

Steaming induced an increase in Zn bioaccessibility for tuna and plaice, but a reduction was observed for octopus and mussel. This is consistent with previous findings of Amiard et al. (2008) in shellfish. In contrast, Cu bioaccessibility seems not to be affected by steaming, in contrast to previous results obtained for fish and shellfish (He et al., 2010; He and Wang, 2013). Differences in seafood matrix composition can be a reliable justification for this unchanged of $\mathrm{Cu}$ bioaccessibility, as $\mathrm{Cu}$ is mainly associated to metallothioneins and insoluble ligands in the form of less degradable complexes. However, the most severe heating conditions (e.g. frying or grilling) have been reported to cause a decrease in $\mathrm{Cu}$ and $\mathrm{Zn}$ bioaccessibility (Amiard et al., 2008). In hake, tuna, monkfish, mussel and shrimp, steaming does not seem to affect Se 
bioaccessibility, as observed for blue shark (Matos et al. 2015), seabass and red seabream (He et al. 2010). In contrast, steaming decreased Se bioaccessibility in plaice and shrimp (He \& Wang, 2013).

Besides the reasonable high levels of $\mathrm{Zn}$ and Fe observed for the seaweed $L$. digitata, this species can also be a good source of $\mathrm{Sr}$ and I, though the concentrations were higher in the newer leafs. Low Sr concentrations were also observed in fish and shellfish (Agusa et al., 2007; Guerin et al., 2011; Qin et al., 2015). Laminaria digitata and Laminaria hyperborea seaweeds have been described as very important sources of I (Maehre et al., 2016). In fact, I is an essential bioactive element used in biosynthesis of thyroid hormones, and a lack of I leads to thyroid disorders (Zimmermann, 2009, 2010). A previous study performed with boiled Japanese tangle (Laminaria japonica) revealed $54 \%$ of bioaccessible I (Fukushima and Chatt, 2012), which was lower than values obtained in the current study. However, the current study reveals that the part of seaweed being analysed play an important role in I bioaccessibility, as the levels were in the older part increased (80\%) significantly after steaming.

\subsection{Relationship between trace elements concentration and bioaccessibility}

Previous studies in fish and shellfish showed no correlation between element concentration and bioaccessibility (He and Wang, 2013; Laird and Chan, 2013), which is in accordance to results obtained for 8 elements in the current study. In contrast, other authors demonstrated a significant positive correlation between the element concentration and bioaccessibility for $\mathrm{Cd}$ in fish (He et al., 2010) and mussel digestive gland (Amiard et al., 2008), which was also observed in the current work for steamed seafood. However, a negative correlation was observed between the bioaccessibility and 
Cd concentration in oysters (Gao et al., 2014). In mussels and clams, $\mathrm{Cu}$ concentration revealed significant negative correlation between the element concentration and its bioaccessibility. The food matrix composition and variability between the seafood species can justify the existence or absence of correlation between concentration and bioaccessibility (He \& Wang, 2013).

\section{$\underline{4.5 . ~ S e l e n i u m ~ a n d ~ m e r c u r y ~ b a l a n c e ~}$}

Selenium has been associated to the reduction of $\mathrm{Hg}$ toxicity (Ralston et al., 2016). The molar ratio between $\mathrm{Se}$ and $\mathrm{Hg}(\mathrm{Se}: \mathrm{Hg}$; $\mathrm{Se}: \mathrm{MeHg}$ ) has been suggested as an essential criteria to evaluate the health risks raised by $\mathrm{Hg}$ (Ralston et al., 2007). In the present study, all five predatory species had Se:Hg and Se:MeHg molar ratios above 1, showing that $\mathrm{Se}$ molar content exceeded $\mathrm{Hg}$ molar content. Similar findings were described in other species, such as tuna, Mediterranean scaldfish, red mullet, European anchovy, Atlantic hourse mackerel, and grey-eel catfish (Afonso et al., 2015; Copat et al., 2014; Looi et al., 2016). This ratio increased with bioaccessibility, due to the reduction of $\mathrm{MeHg}$ bioaccessibility after steaming. Cabañero and co-authors (2004) observed a similar increase in Se:Hg ratio in bioaccessible swordfish, tuna and sardine. Moreover, steaming increased the Se:MeHg in tuna, mackerel and octopus, suggesting that this culinary treatment is a good strategy to reduce the toxic effect of $\mathrm{MeHg}$. Selenium health benefit value $\left(\mathrm{HBV}_{\mathrm{Se}}\right)$, based on the molar concentrations of $\mathrm{Hg} / \mathrm{MeHg}$ and Se found in seafood is a risk assessment tool used to evaluate the effects of $\mathrm{MeHg}$ exposure after seafood consumption (Ralston et al., 2016). Indeed, a low Se intake is generally associated with a high $\mathrm{MeHg}$ exposure, and during pregnancy it can result in severe negative effects for fetal tissues (Crump et al., 1998). In this study, the analysed 
seafood species presented positive $\mathrm{HBV}_{\mathrm{Se}}$ values, suggesting that consuming these species can reduce the risks associated with the inhibition of selenoenzymes by $\mathrm{MeHg}$. The molar ratio excess of $\mathrm{Se}$ in comparison to $\mathrm{Hg}$ has also been verified in other pelagic fish (Copat et al., 2014; Kaneko and Ralston, 2007; Looi et al., 2016; Ordiano-Flores et al., 2012; Ralston et al., 2007; Ralston and Raymond, 2014).

\subsection{Benefit-risk balance}

$\mathrm{Zn}, \mathrm{Cu}, \mathrm{Se}, \mathrm{Fe}, \mathrm{I}$ and $\mathrm{Mn}$ are essential micronutrients for the human body and appropriate intake of these elements should be provided in a balanced diet to meet the consumers' daily requirements (EFSA, 2006). In this sense, considering seafood's elemental profiles, the studied fish, mollusc and crustacean species showed to be good sources of Se, which plays an important role against oxidative stress, in the regulation of thyroid hormones' action, and as an antagonist in MeHg exposure (e.g. Ralston et al., 2016). Yet, considering the dichotomy in essential elements benefit-risk assessment, i.e. the need to accomplish appropriate element intakes that are neither too low, causing nutritional deficiencies, nor too high, being toxic to consumers, some fish species such as tuna should be consumed parsimoniously to avoid exceeding the UL set for Se (EFSA, 2006). The same principle can also be applied for $\mathrm{Cu}$ in octopus and shrimps, as well as mussels and for seaweeds due to the remarkably high levels of I.

Regarding $\mathrm{MeHg}$ and $\mathrm{Cd}$, which have no known biological role in the human body, out of the studied seafood species, the consumption of octopus showed to place consumers at a higher risk of exceeding the TWI set for $\mathrm{MeHg}$, whereas the consumption of $150 \mathrm{~g}$ of mussels revealed Cd intakes closest to the TWI. Nevertheless, in agreement with previous studies (e.g. Maulvault et al., 2011, 2013), results clearly 
showed that, on the one hand, cooking procedures may induce notorious changes in seafood elemental profiles and, on the other hand, only a fraction of the initial element content may be available to be absorbed by the human intestinal epithelia after digestion (i.e. bioaccessible).

\section{Conclusions}

The bioaccessibility of toxic and essential elements in different seafood matrices, including fish, shellfish and seaweeds, was influenced by species and greatly varied between elements. $\mathrm{MeHg}$ revealed low bioaccessibility in all fish species. In contrast, As bioaccessibility was high in all species. Therefore, future studies should assess if inorganic As bioaccessibility follows the same trend. In the case of essential elements, overall bioaccessibility showed high values in fish and seaweed (for $\mathrm{Zn}, \mathrm{Mn}$ and I), whereas lower values and wider variation was found among shellfish.

Steaming affected differentially the elements bioaccessibility. $\mathrm{MeHg}$ and $\mathrm{Cd}$ levels were reduced in steamed seafood, thus lowering the health risks when seafood is consumed with this culinary practice. In contrast, for essential elements, steaming increased (e.g. $\mathrm{Zn}$ in fish and seaweed; $\mathrm{Sr}$ in plaice, $\mathrm{Mn}$ in seaweed old), decreased (e.g. $\mathrm{Zn}$ in shellfish, Se in plaice and shrimp, $\mathrm{Mn}, \mathrm{Sr}$ and $\mathrm{Fe}$ in mussel) or unchanged (e.g. Se some fish and mollusc; $\mathrm{Cu}$ and I for almost seafood species) the bioaccessibility, according to seafood species.

In general, fish, shellfish and seaweed species can be considered as reasonable sources of essential elements. Steamed mussels, shrimp, octopus and tuna are an added value to human health. Hake was the species in the present study with lowest essential elements bioaccessible concentrations. Tuna can be a reasonable source of $\mathrm{Zn}, \mathrm{Se}, \mathrm{Cu}$ 
and I, and low $\mathrm{MeHg}$ and $\mathrm{Cd}$ bioaccessibility was observed in this species. Newer segments of the seaweed showed to be more enriched in essential elements but lower in arsenic content. Moreover, a low health hazard was associated to the five predatory species consumption as shown by the positive $\mathrm{HBV}_{\mathrm{Se}}$ and high molar Se:MeHg ratio. The present seafood species are a valuable source of iodine particularly in the geographical areas where iodine intakes from other foods are insufficient, however it is desirable to do it in an equilibrated and balanced diet, as some of these species showed very high I levels.

Finally, as far as elements are concerned, the steamed seafood species studied in this work are recommended to be regularly consumed as this culinary method reduces the bioaccessibility of toxic elements and, whenever available, most essential elements are maintained at high concentrations after digestion. This study clearly reveals that food risk and benefit assessment should take into consideration the diversity of seafood species, the effects of culinary treatment and the bioaccessibility of the compounds under study to provide more accurate indications about health effects to consumers, refinements of food safety legislation (MPCs and TWIs/RDIs) and guidelines for consumers regarding seafood consumption, thus minimizing under- or overestimations of risks/benefits, and providing more realistic information.

\section{Acknowledgments}

The research leading to these results has received funding from the European Union Seventh Framework Programme (FP7/2007-2013) under the ECsafeSEAFOOD project (grant agreement $n^{\circ}$ 311820). The Portuguese Foundation for Science and Technology 
supported the Ph.D. Grant of ALM (SFRH/BD/103569/2014). ANFACO for providing hake, tuna and shrimp; Istituto Delta for providing mackerel used in this study.

\section{References}

Afonso, C., Costa, S., Cardoso, C., Bandarra, N.M., Batista, I., Coelho, I., Castanheira, I., Nunes, M.L., 2015. Evaluation of the risk/benefit associated to the consumption of raw and cooked farmed meagre based on the bioaccessibility of selenium, eicosapentaenoic acid and docosahexaenoic acid, total mercury, and methylmercury determined by an in vitro digestion model. Food chemistry 170, 249256.

Agusa, T., Kunito, T., Sudaryanto, A., Monirith, I., Kan-Atireklap, S., Iwata, H., Ismail, A., Sanguansin, J., Muchtar, M., Tana, T.S., Tanabe, S., 2007. Exposure assessment for trace elements from consumption of marine fish in Southeast Asia. Environmental pollution 145, 766-777.

Amiard, J.C., Amiard-Triquet, C., Charbonnier, L., Mesnil, A., Rainbow, P.S., Wang, W.X., 2008. Bioaccessibility of essential and non-essential metals in commercial shellfish from Western Europe and Asia. Food Chem Toxicol 46, 2010-2022.

Anacleto, P., Lourenco, H.M., Ferraria, V., Afonso, C., Carvalho, M.L., Martins, M.F., Nunes, M.L., 2009. Total Arsenic Content in Seafood Consumed in Portugal. J Aquat Food Prod T 18, 32-45. 
Braga, A.C., Alves, R.N., Maulvault, A.L., Barbosa, V., Marques, A., Costa, P.R.,

2016. In vitro bioaccessibility of the marine biotoxin okadaic acid in shellfish. Food Chem Toxicol 89, 54-59.

Cabanero, A.I., Madrid, Y., Camara, C., 2004. Selenium and mercury bioaccessibility in fish samples: an in vitro digestion method. Anal Chim Acta 526, 5161.

Cabanero, A.I., Madrid, Y., Camara, C., 2007. Mercury-selenium species ratio in representative fish samples and their bioaccessibility by an in vitro digestion method. Biol Trace Elem Res 119, 195-211.

Calatayud, M., Devesa, V., Virseda, J.R., Barbera, R., Montoro, R., Velez, D., 2012. Mercury and selenium in fish and shellfish: occurrence, bioaccessibility and uptake by Caco-2 cells. Food Chem Toxicol 50, 2696-2702.

Cano-Sancho, G., Perello, G., Maulvault, A.L., Marques, A., Nadal, M., Domingo, J.L., 2015. Oral bioaccessibility of arsenic, mercury and methylmercury in marine species commercialized in Catalonia (Spain) and health risks for the consumers. Food and chemical toxicology: an international journal published for the British Industrial Biological Research Association 86, 34-40.

Cardoso, C., Afonso, C., Lourenco, H., Costa, S., Nunes, M.L., 2015. Bioaccessibility assessment methodologies and their consequences for the risk-benefit evaluation of food. Trends Food Sci Tech 41, 5-23. 
Cardoso, C., Farias, I., Costa, V., Nunes, M., Gordo, L., 2010. Estimation of Risk Assessment of Some Heavy Metals Intake Through Black Scabbardfish (Aphanopus carbo) Consumption in Portugal. Risk Anal 30, 952-961.

Cardoso, P.S.D., Januario, J.N., de Lima, K.C.S., Januario, M.C., de Aguiar, R.A.L.P., Costa, V.F.M., Behrens, O., Viana, M.B., 2013. Maternal and Perinatal Outcome in Pregnant Women with Sickle Cell Disease and Risk Assessment of near Miss or Maternal Death: Prospective Study of Project Aninha in Minas Gerais, Brazil. Am J Hematol 88, E14-E14.

Celik, U., Oehlenschlager, J., 2007. High contents of cadmium, lead, zinc and copper in popular fishery products sold in Turkish supermarkets. Food Control 18, 258261.

Chapman, L., Chan, H.M., 2000. The influence of nutrition on methyl mercury intoxication. Environ Health Persp 108, 29-56.

Collins, C.D., Craggs, M., Garcia-Alcega, S., Kademoglou, K., Lowe, S., 2015. 'Towards a unified approach for the determination of the bioaccessibility of organic pollutants'. Environment international 78, 24-31.

Copat, C., Vinceti, M., D'Agati, M.G., Arena, G., Mauceri, V., Grasso, A., Fallico, R., Sciacca, S., Ferrante, M., 2014. Mercury and selenium intake by seafood from the Ionian Sea: A risk evaluation. Ecotoxicol Environ Saf 100, 87-92. 
Costa Fdo, N., Korn, M.G., Brito, G.B., Ferlin, S., Fostier, A.H., 2016. Preliminary results of mercury levels in raw and cooked seafood and their public health impact. Food chemistry 192, 837-841.

Crump, K.S., Kjellstrom, T., Shipp, A.M., Silvers, A., Stewart, A., 1998. Influence of prenatal mercury exposure upon scholastic and psychological test performance: benchmark analysis of a New Zealand cohort. Risk Anal 18, 701-713.

EFSA, 2006. Tolerable upper intake levels for vitamins and minerals. Available from:

http://www.efsa.europa.eu/sites/default/files/efsa_rep/blobserver_assets/ndatolerableuil. pdf (Acessed: 31 May 2016).

EFSA, 2009a. Scientific opinion of the panel on arsenic in food. EFSA J., 7 (10) (2009), 1351.

EFSA, 2009b. Scientific opinion of the panel on contaminants in the food chain on a request from the european commission on cadmium in food. EFSA J., 980 (2009), $1-139$.

EFSA, 2011. Scientific opinion. Statement on tolerable weekly intake for cadmium. European Food Safety Agency Journal, 9(2), 1975. 
EFSA, 2012. EFSA panel on contaminants in the food chain (CONTAM). Scientific opinion on the risk for public health related to the presence of mercury and methylmercury in food. EFSA J., 10 (12) (2012), 2985.

Fraga, C.G., 2005. Relevance, essentiality and toxicity of trace elements in human health. Molecular aspects of medicine 26, 235-244.

Fukushima, M., Chatt, A., 2012. Estimation of total as well as bioaccessible levels and average daily dietary intake of iodine from Japanese edible seaweeds by epithermal neutron activation analysis. J Radioanal Nucl Ch 294, 471-478.

Gao, S., Wang, W.X., 2014. Oral bioaccessibility of toxic metals in contaminated oysters and relationships with metal internal sequestration. Ecotox Environ Safe 110, 261-268.

Guerin, T., Chekri, R., Vastel, C., Sirot, V., Volatier, J.L., Leblanc, J.C., Noel, L., 2011. Determination of 20 trace elements in fish and other seafood from the French market. Food chemistry 127, 934-942.

He, K., Song, Y., Daviglus, M.L., Liu, K., Van Horn, L., Dyer, A.R., Goldbourt, U., Greenland, P., 2004. Fish consumption and incidence of stroke: a meta-analysis of cohort studies. Stroke; a journal of cerebral circulation 35, 1538-1542. 
He, M., Ke, C.H., Tian, L., Li, H.B., 2015. Bioaccessibility and Health Risk Assessment of $\mathrm{Cu}, \mathrm{Cd}$, and $\mathrm{Zn}$ in "Colored" Oysters. Archives of environmental contamination and toxicology 70, 595-606.

He, M., Ke, C.H., Wang, W.X., 2010. Effects of Cooking and Subcellular Distribution on the Bioaccessibility of Trace Elements in Two Marine Fish Species. J Agr Food Chem 58, 3517-3523.

He, M., Wang, W.X., 2013. Bioaccessibility of 12 trace elements in marine molluscs. Food Chem Toxicol 55, 627-636.

Jadan-Piedra, C., Clemente, M.J., Devesa, V., Velez, D., 2016. Influence of Physiological Gastrointestinal Parameters on the Bioaccessibility of Mercury and Selenium from Swordfish. J Agr Food Chem 64, 690-698.

Kaneko, J.J., Ralston, N.V., 2007. Selenium and mercury in pelagic fish in the central north pacific near Hawaii. Biol Trace Elem Res 119, 242-254.

Kulp, K.S., Fortson, S.L., Knize, M.G., Felton, J.S., 2003. An in vitro model system to predict the bioaccessibility of heterocyclic amines from a cooked meat matrix. Food Chem Toxicol 41, 1701-1710.

Kwasniak, J., Falkowska, L., Kwasniak, M., 2012. The assessment of organic mercury in Baltic fish by use of an in vitro digestion model. Food chemistry 132, 752758. 
Laird, B.D., Chan, H.M., 2013. Bioaccessibility of metals in fish, shellfish, wild game, and seaweed harvested in British Columbia, Canada. Food Chem Toxicol 58, 381-387.

Laparra, J.M., Velez, D., Barbera, R., Montoro, R., Farre, R., 2007. Bioaccessibility and transport by Caco-2 cells of organoarsenical species present in seafood. J Agr Food Chem 55, 5892-5897.

Laparra, J.M., Velez, D., Montoro, R., Barbera, R., Farre, R., 2003. Estimation of arsenic bioaccessibility in edible seaweed by an in vitro digestion method. J Agr Food Chem 51, 6080-6085.

Larsen, R., Eilertsen, K.E., Elvevoll, E.O., 2011. Health benefits of marine foods and ingredients. Biotechnology advances 29, 508-518.

Leufroy, A., Noel, L., Beauchemin, D., Guerin, T., 2012. Bioaccessibility of total arsenic and arsenic species in seafood as determined by a continuous online leaching method. Anal Bioanal Chem 402, 2849-2859.

Looi, L.J., Aris, A.Z., Haris, H., Yusoff, F.M., Hashim, Z., 2016. The levels of mercury, methylmercury and selenium and the selenium health benefit value in grey-eel catfish (Plotosus canius) and giant mudskipper (Periophthalmodon schlosseri) from the Strait of Malacca. Chemosphere 152, 265-273. 
Lund, E.K., 2013. Health benefits of seafood; is it just the fatty acids? Food chemistry $140,413-420$.

Maehre, H.K., Edvinsen, G.K., Eilertsen, K.E., Elvevoll, E.O., 2016. Heat treatment increases the protein bioaccessibility in the red seaweed dulse (Palmaria palmata), but not in the brown seaweed winged kelp (Alaria esculenta). J Appl Phycol $28,581-590$.

Marques, A., Lourenco, H.M., Nunes, M.L., Roseiro, C., Santos, C., Barranco, A., Rainieri, S., Langerholc, T., Cencic, A., 2011. New tools to assess toxicity, bioaccessibility and uptake of chemical contaminants in meat and seafood. Food Res Int $44,510-522$.

Marval-Leon, J.R., Camara-Martos, F., Amaro-Lopez, M.A., Moreno-Rojas, R., 2014. Bioaccessibility and content of Se in fish and shellfish widely consumed in Mediterranean countries: influence of proteins, fat and heavy metals. International journal of food sciences and nutrition 65, 678-685.

Matos, J., Lourenco, H.M., Brito, P., Maulvault, A.L., Martins, L.L., Afonso, C., 2015. Influence of bioaccessibility of total mercury, methyl-mercury and selenium on the risk/benefit associated to the consumption of raw and cooked blue shark (Prionace glauca). Environmental research 143, 123-129.

Maulvault, A.L., Anacleto, P., Barbosa, V., Sloth, J.J., Rasmussen, R.R., Tediosi, A., Fernandez-Tejedor, M., van den Heuvel, F.H., Kotterman, M., Marques, A., 2015. 
Toxic elements and speciation in seafood samples from different contaminated sites in Europe. Environmental research 143, 72-81.

Maulvault, A.L., Cardoso, C., Nunes, M.L., Marques, A., 2013. Risk-benefit assessment of cooked seafood: Black scabbard fish (Aphanopus carbo) and edible crab (Cancer pagurus) as case studies. Food Control 32, 518-524.

Maulvault, A.L., Machado, R., Afonso, C., Lourenco, H.M., Nunes, M.L., Coelho, I., Langerholc, T., Marques, A., 2011. Bioaccessibility of $\mathrm{Hg}, \mathrm{Cd}$ and $\mathrm{As}$ in cooked black scabbard fish and edible crab. Food Chem Toxicol 49, 2808-2815.

Metian, M., Charbonnier, L., Oberhaensli, F., Bustamante, P., Jeffree, R., Amiard, J.C., Warnau, M., 2009. Assessment of metal, metalloid, and radionuclide bioaccessibility from mussels to human consumers, using centrifugation and simulated digestion methods coupled with radiotracer techniques. Ecotox Environ Safe 72, 14991502.

Minekus, M., Alminger, M., Alvito, P., Ballance, S., Bohn, T., Bourlieu, C., Carriere, F., Boutrou, R., Corredig, M., Dupont, D., Dufour, C., Egger, L., Golding, M., Karakaya, S., Kirkhus, B., Le Feunteun, S., Lesmes, U., Macierzanka, A., Mackie, A., Marze, S., McClements, D.J., Menard, O., Recio, I., Santos, C.N., Singh, R.P., Vegarud, G.E., Wickham, M.S.J., Weitschies, W., Brodkorb, A., 2014. A standardised static in vitro digestion method suitable for food - an international consensus. Food Funct 5, $1113-1124$. 
Moreda-Pineiro, J., Moreda-Pineiro, A., Romaris-Hortas, V., DominguezGonzalez, R., Alonso-Rodriguez, E., Lopez-Mahia, P., Muniategui-Lorenzo, S., PradaRodriguez, D., Bermejo-Barrera, P., 2012. Trace metals in marine foodstuff: Bioavailability estimation and effect of major food constituents. Food chemistry 134, $339-345$.

Olmedo, P., Hernandez, A.F., Pla, A., Femia, P., Navas-Acien, A., Gil, F., 2013. Determination of essential elements (copper, manganese, selenium and zinc) in fish and shellfish samples. Risk and nutritional assessment and mercury-selenium balance. Food Chem Toxicol 62, 299-307.

Ordiano-Flores, A., Rosiles-Martinez, R., Galvan-Magana, F., 2012. Biomagnification of mercury and its antagonistic interaction with selenium in yellowfin tuna Thunnus albacares in the trophic web of Baja California Sur, Mexico. Ecotoxicol Environ Saf 86, 182-187.

Ouedraogo, O., Amyot, M., 2011. Effects of various cooking methods and food components on bioaccessibility of mercury from fish. Environmental research 111, 1064-1069.

Oomen A.G., Rompelberg C.J.M., Bruil M.A., Dobbe C.J.G., Pereboom D.P.K.H., Sips A.J.A.M., 2003. Development of an in vitro digestion model for estimation of bioaccessibility of soil contaminants. Arch Environ Contam Toxicol 44, 281-287 
Peng, Q., Nunes, L.M., Greenfield, B.K., Dang, F., Zhong, H., 2016. Are Chinese consumers at risk due to exposure to metals in crayfish? A bioaccessibility-adjusted probabilistic risk assessment. Environment international 88, 261-268.

Qin, Y.Y., Leung, C.K.M., Lin, C.K., Wong, M.H., 2015. The associations between metals/metalloids concentrations in blood plasma of Hong Kong residents and their seafood diet, smoking habit, body mass index and age. Environ Sci Pollut R 22, 13204-13211.

Ralston, N.V., Blackwell, J.L., 3rd, Raymond, L.J., 2007. Importance of molar ratios in selenium-dependent protection against methylmercury toxicity. Biol Trace Elem Res 119, 255-268.

Ralston, N.V., Ralston, C.R., Raymond, L.J., 2016. Selenium Health Benefit Values: Updated Criteria for Mercury Risk Assessments. Biol Trace Elem Res 171, 262-269.

Ralston, N.V., Raymond, L.J., 2014. Selenium status and intake influences

mercury exposure risk assessments. In G. S. Bañuelos, Z.-Q. Lin, \& X. Yin (Eds.),

Selenium in the environment and Human health (pp. 203-205). London, UK:

Taylor \& Francis Group.

Saint-Denis, T., Goupy, J., 2004. Optimization of a nitrogen analyser based on the Dumas method. Anal Chim Acta 515, 191-198. 
Scerbo, R., Barghigiani, C., 1998. Organic mercury determination in fish samples using an automatic mercury analyser. Environ Technol 19, 339-342.

Siedlikowski, M., Bradley, M., Basu, N., 2015. Investigating Bioaccessibility of Methylmercury from Seafood Commonly Consumed in North America. Faseb J 29.

Torres-Escribano, S., Calatayud, M., Ruiz, A., De La Flor, M.T., Devesa, V., Velez, D., Montoro, R., 2010. The effect of cooking on mercury bioaccessible contents of predatory fish. Toxicol Lett 196, S310-S310.

Torres-Escribano, S., Ruiz, A., Barrios, L., Velez, D., Montoro, R., 2011. Influence of mercury bioaccessibility on exposure assessment associated with consumption of cooked predatory fish in Spain. J Sci Food Agr 91, 981-986.

USNAS., 2010. Dietary reference intakes. Recommended intakes for individuals. National Academy of Sciences, Institute of Medicine, Food and Nutrition Board. https://fnic.nal.usda.gov/dietary-guidance/dietary-reference-intakes (Acessed: 1 June 2016)

Usydus, Z., Szlinder-Richert, J., Adamczyk, M., 2009. Protein quality and amino acid profiles of fish products available in Poland. Food chemistry 112, 139-145.

Vandermeersch, G., Lourenco, H.M., Alvarez-Munoz, D., Cunha, S., Diogene, J., Cano-Sancho, G., Sloth, J.J., Kwadijk, C., Barcelo, D., Allegaert, W., Bekaert, K., 
Fernandes, J.O., Marques, A., Robbens, J., 2015. Environmental contaminants of emerging concern in seafood European database on contaminant levels. Environmental research 143, 29-45.

Vazquez, M., Calatayud, M., Piedra, C.J., Chiocchetti, G.M., Velez, D., Devesa, V., 2015. Toxic trace elements at gastrointestinal level. Food Chem Toxicol 86, 163175.

Versantvoort, C.H., Oomen, A.G., Van de Kamp, E., Rompelberg, C.J., Sips, A.J., 2005. Applicability of an in vitro digestion model in assessing the bioaccessibility of mycotoxins from food. Food Chem Toxicol 43, 31-40.

Wang, C., Duan, H.Y., Teng, J.W., 2014. Assessment of microwave cooking on the bioaccessibility of cadmium from various food matrices using an in vitro digestion model. Biol Trace Elem Res 160, 276-284.

WHO, 2012. Biomonitoring-based indicators of exposure to chemical pollutants Report of a Meeting, Catania, Italy, 19-20 April 2012.

Zimmermann, M.B., 2009. Iodine Deficiency. Endocr Rev 30, 376-408.

Zimmermann, M.B., 2010. Iodine deficiency in industrialised countries. P Nutr Soc $69,133-143$. 
Zmozinski, A.V., Carneado, S., Ibanez-Palomino, C., Sahuquillo, A., LopezSanchez, J.F., da Silva, M.M., 2014. Method development for the simultaneous determination of methylmercury and inorganic mercury in seafood. Food Control 46, 351-359.

Legend to supplementary figures:

Supplementary Fig. 1 - Scheme of the in vitro digestion protocol used to access elements bioaccessibility. 
A

Mercury

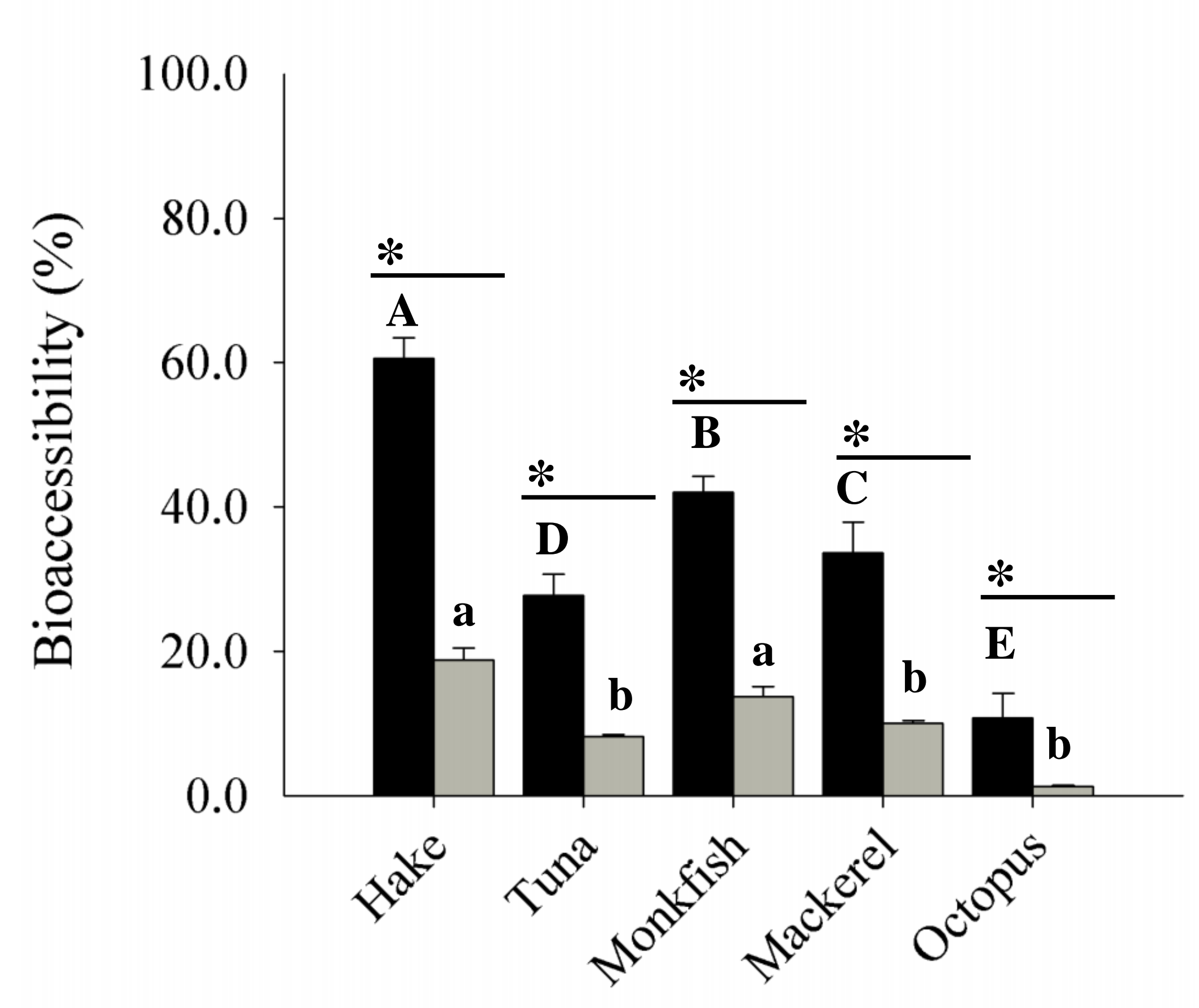

D

Cadmium

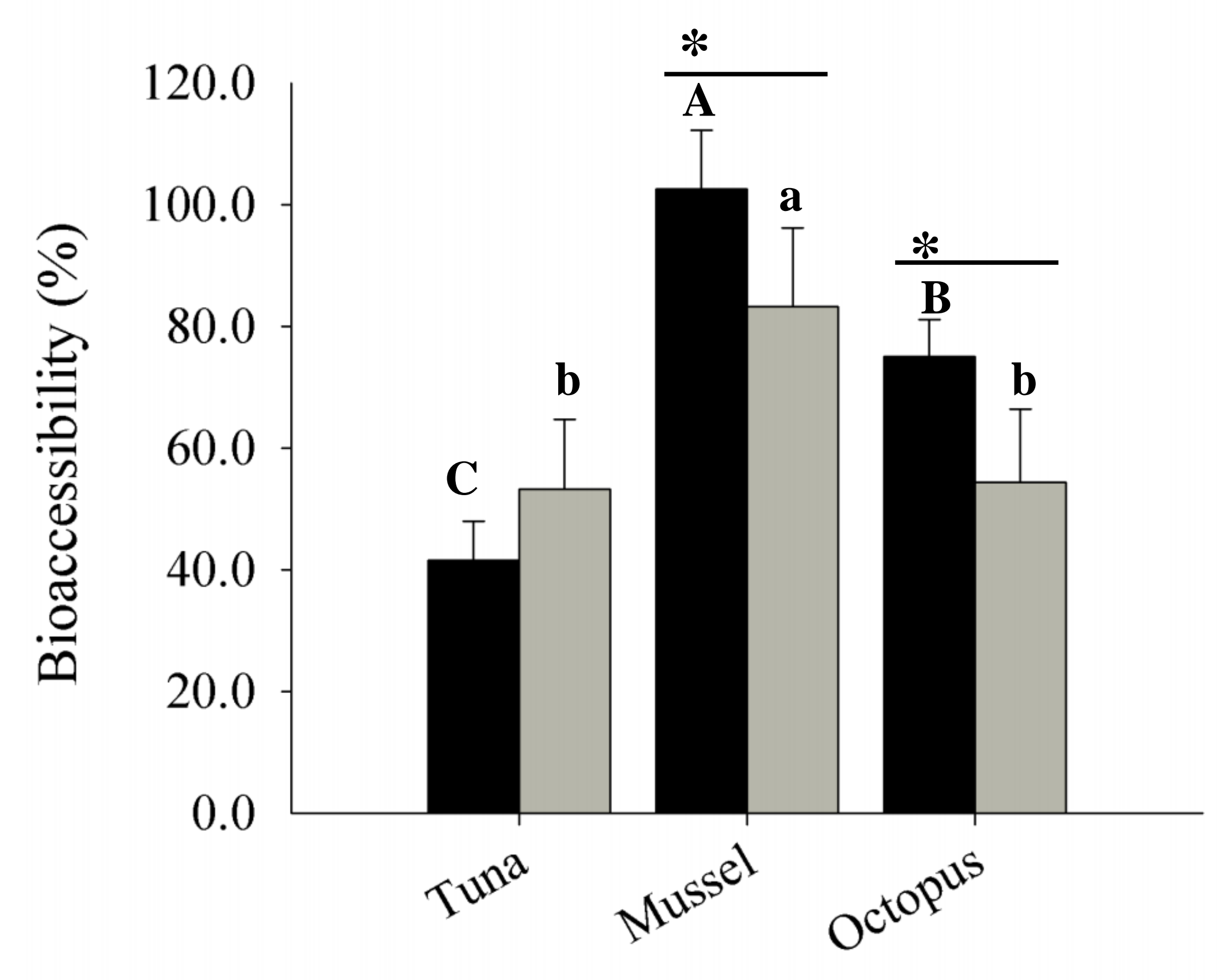

G

Copper

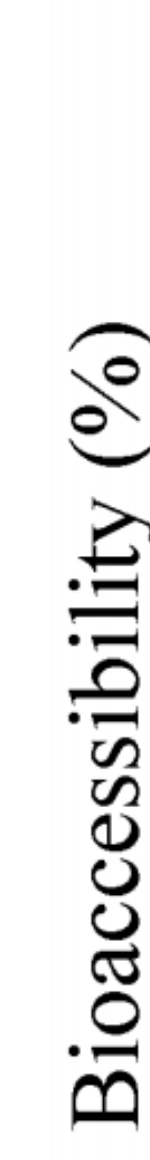

J

Iodine

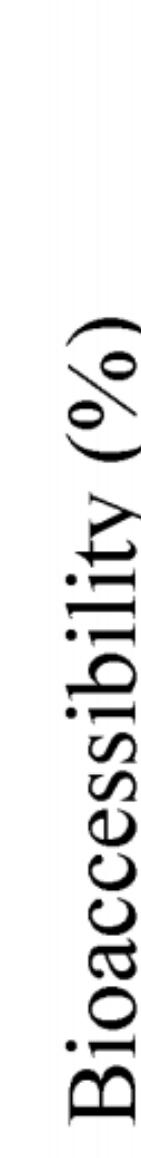

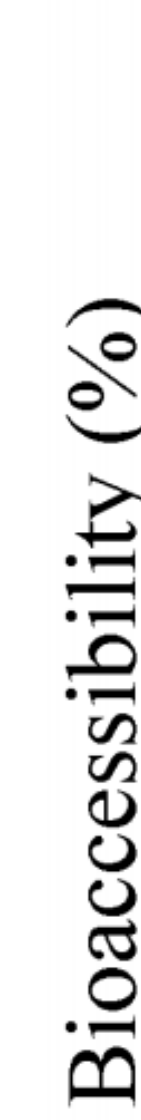

B

Methylmercury

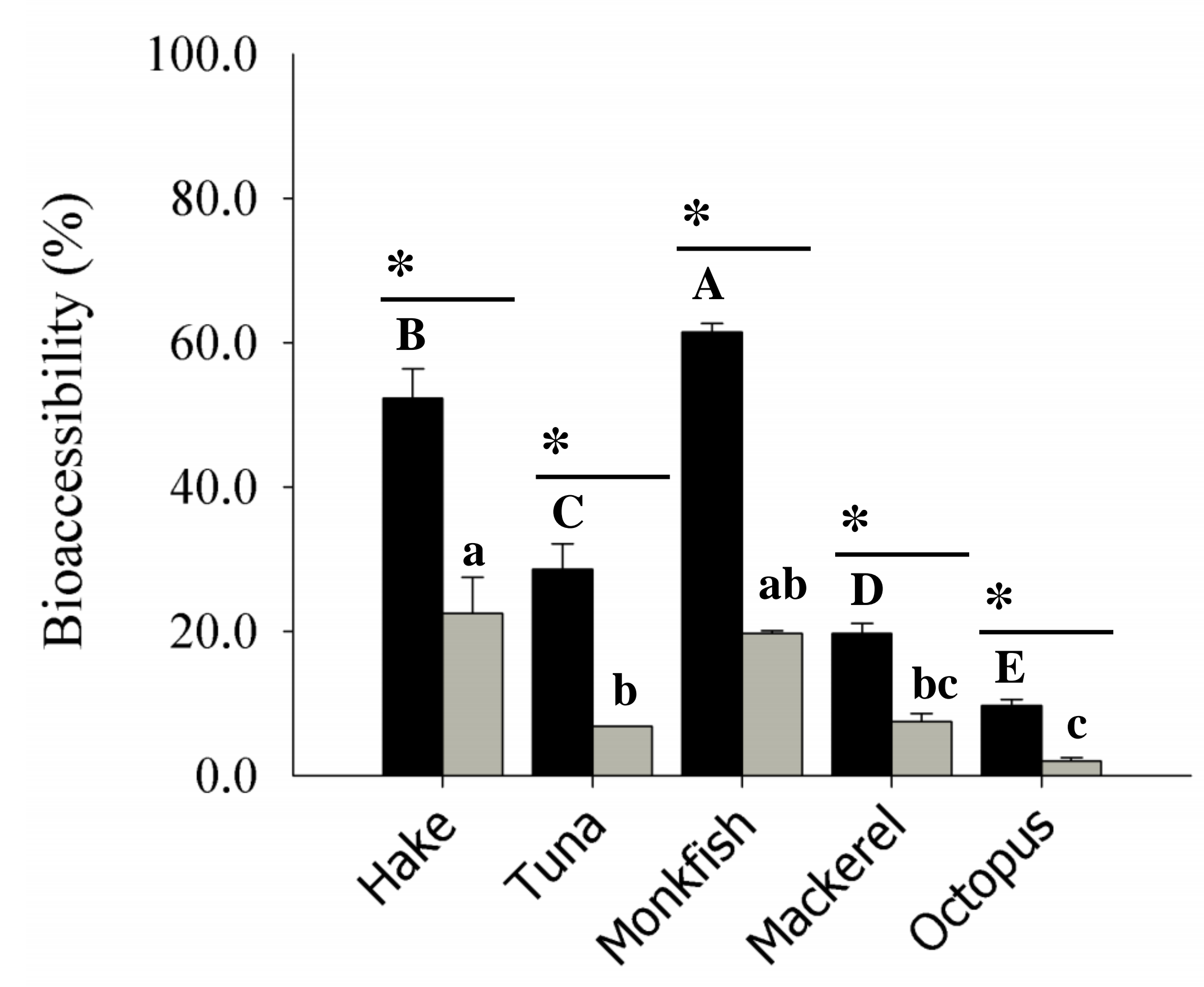

E

\section{Zinc}

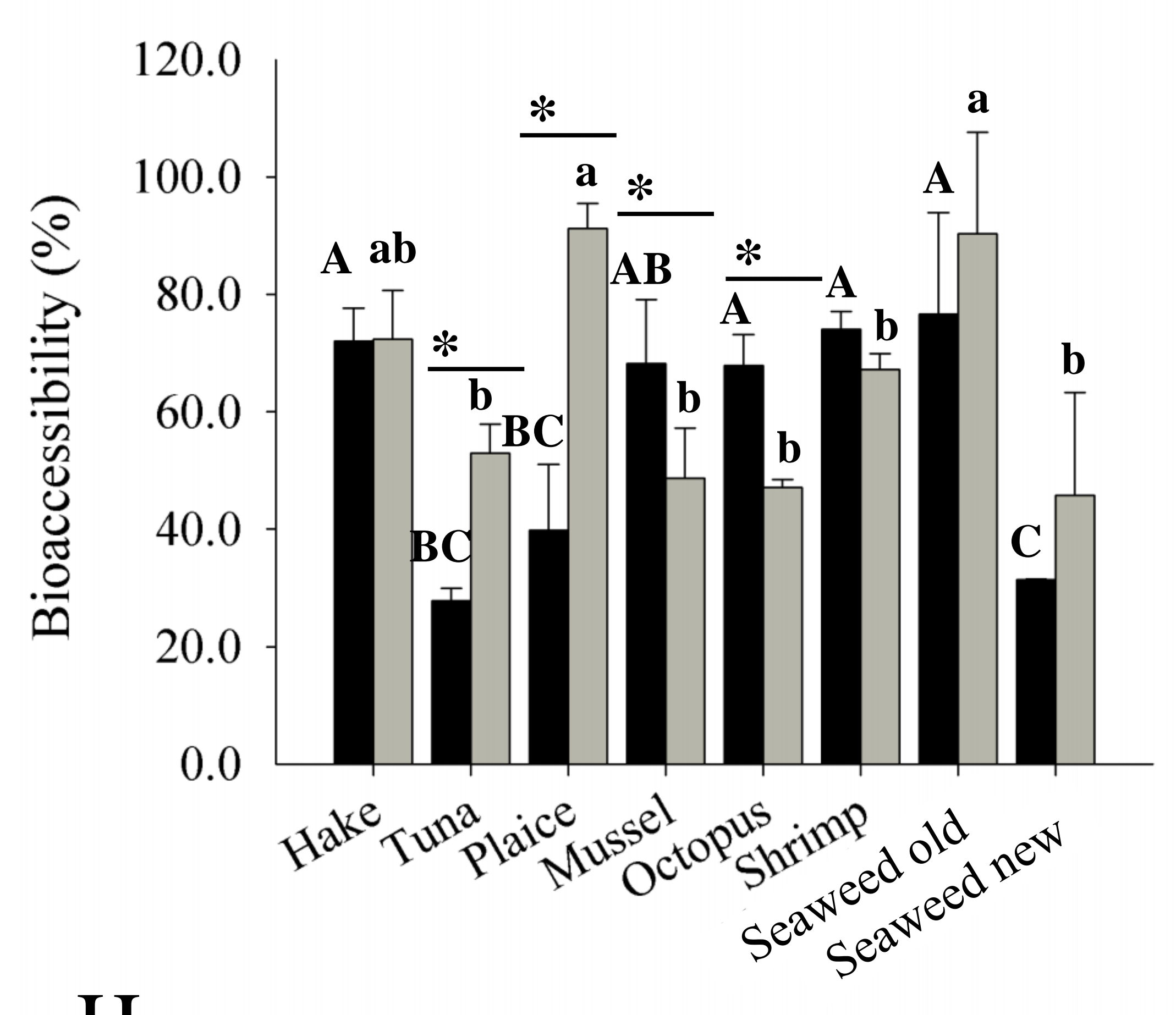

$\mathrm{H}$

Manganese

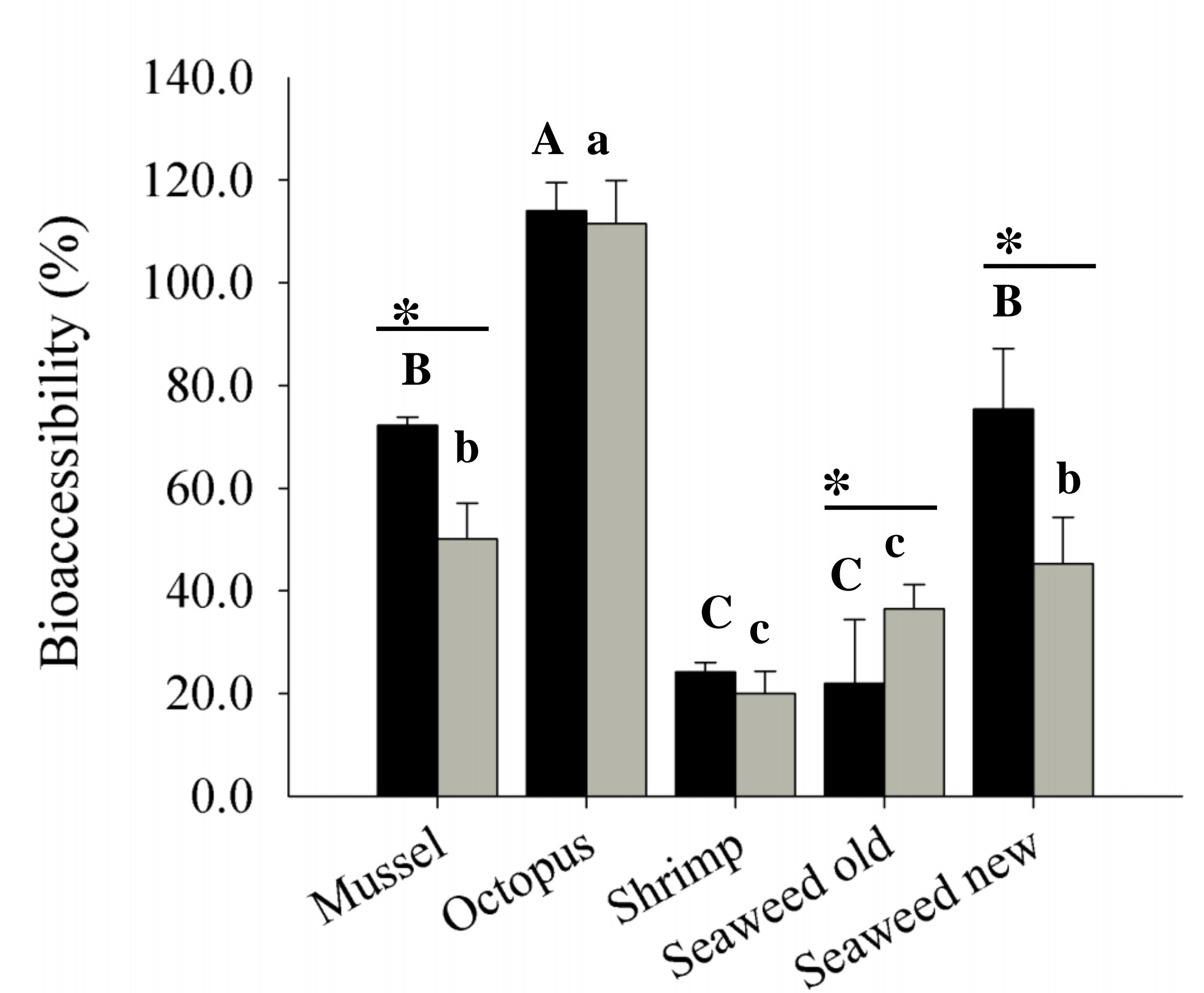

K

Iron

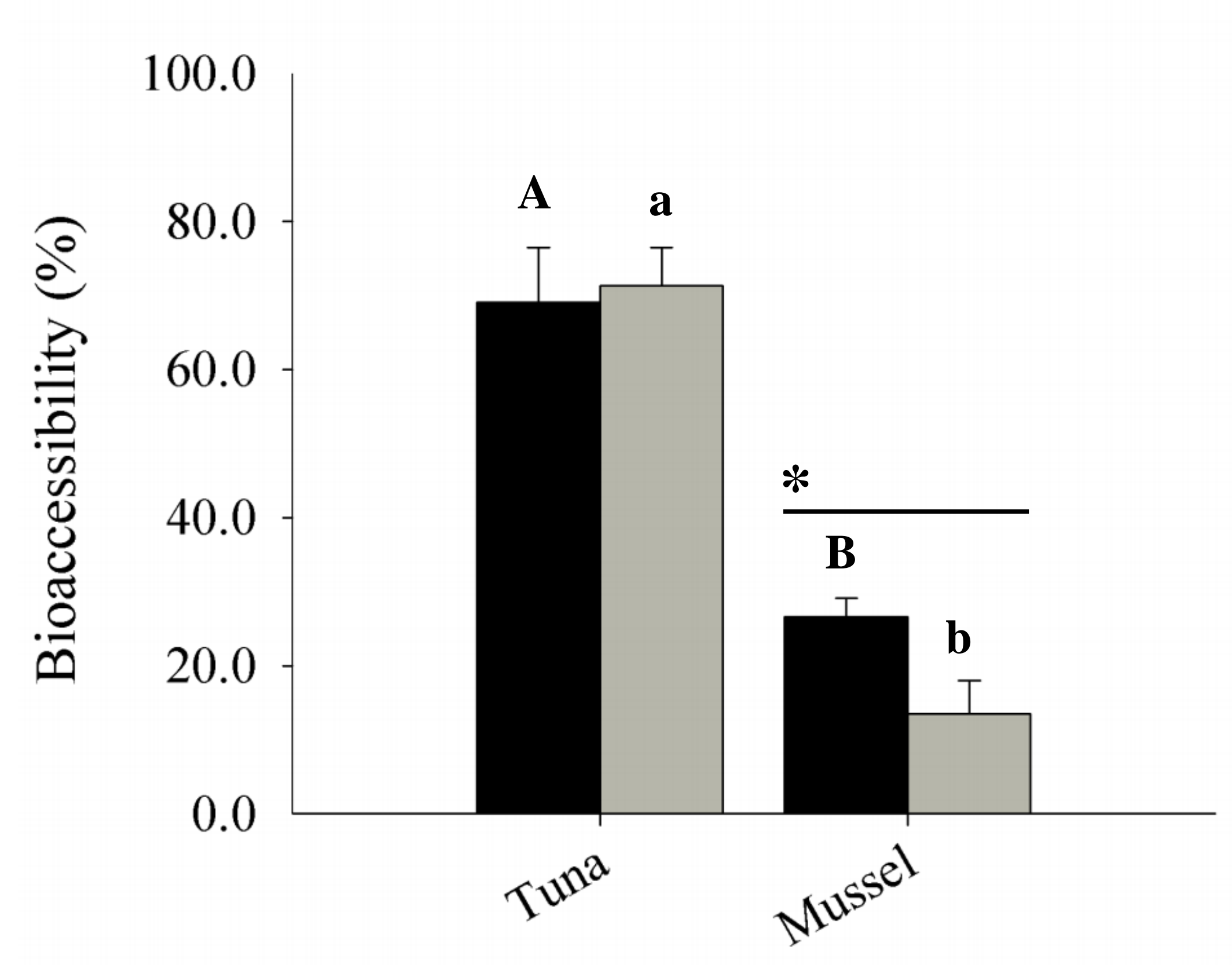

C
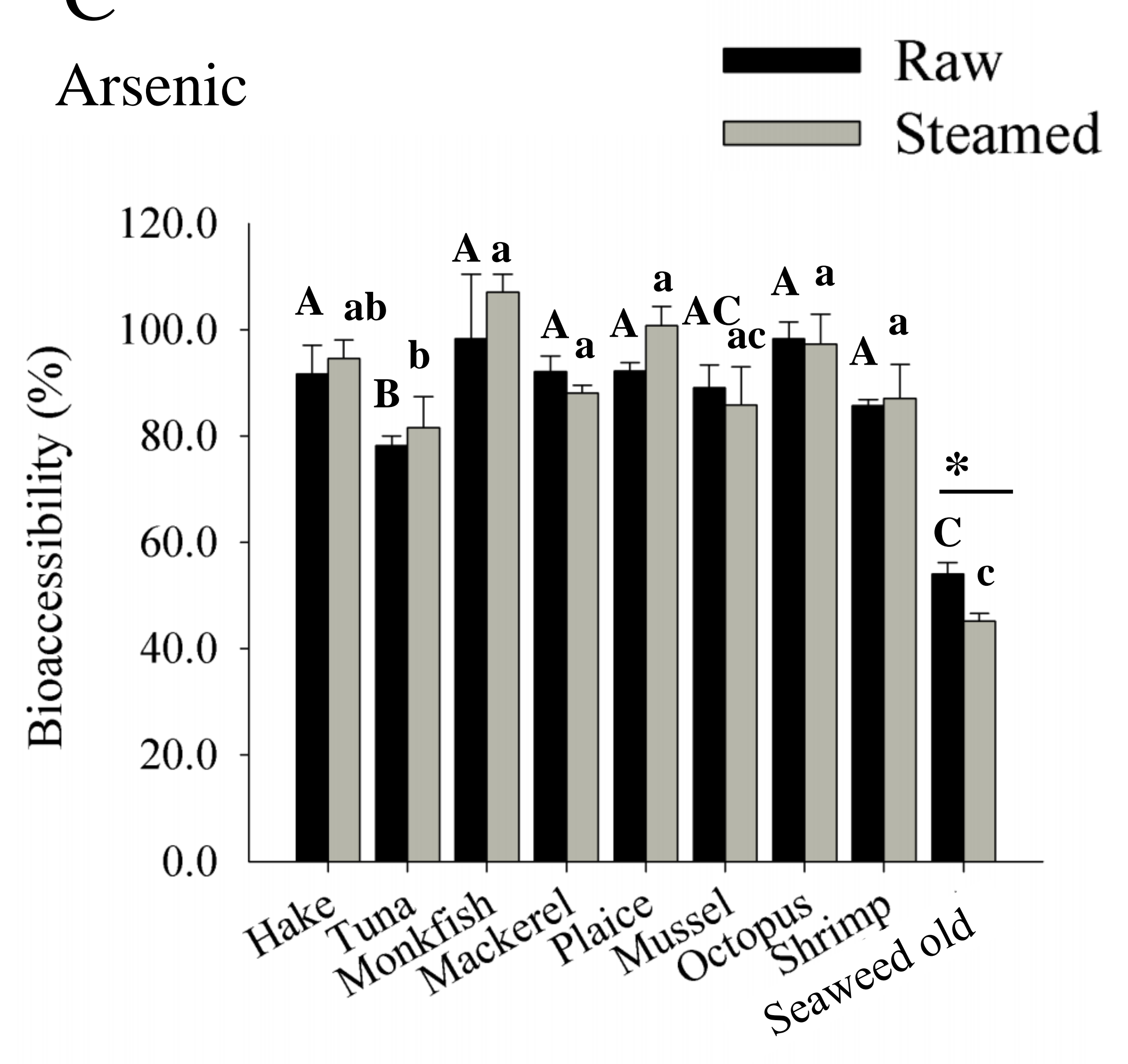

F

Selenium

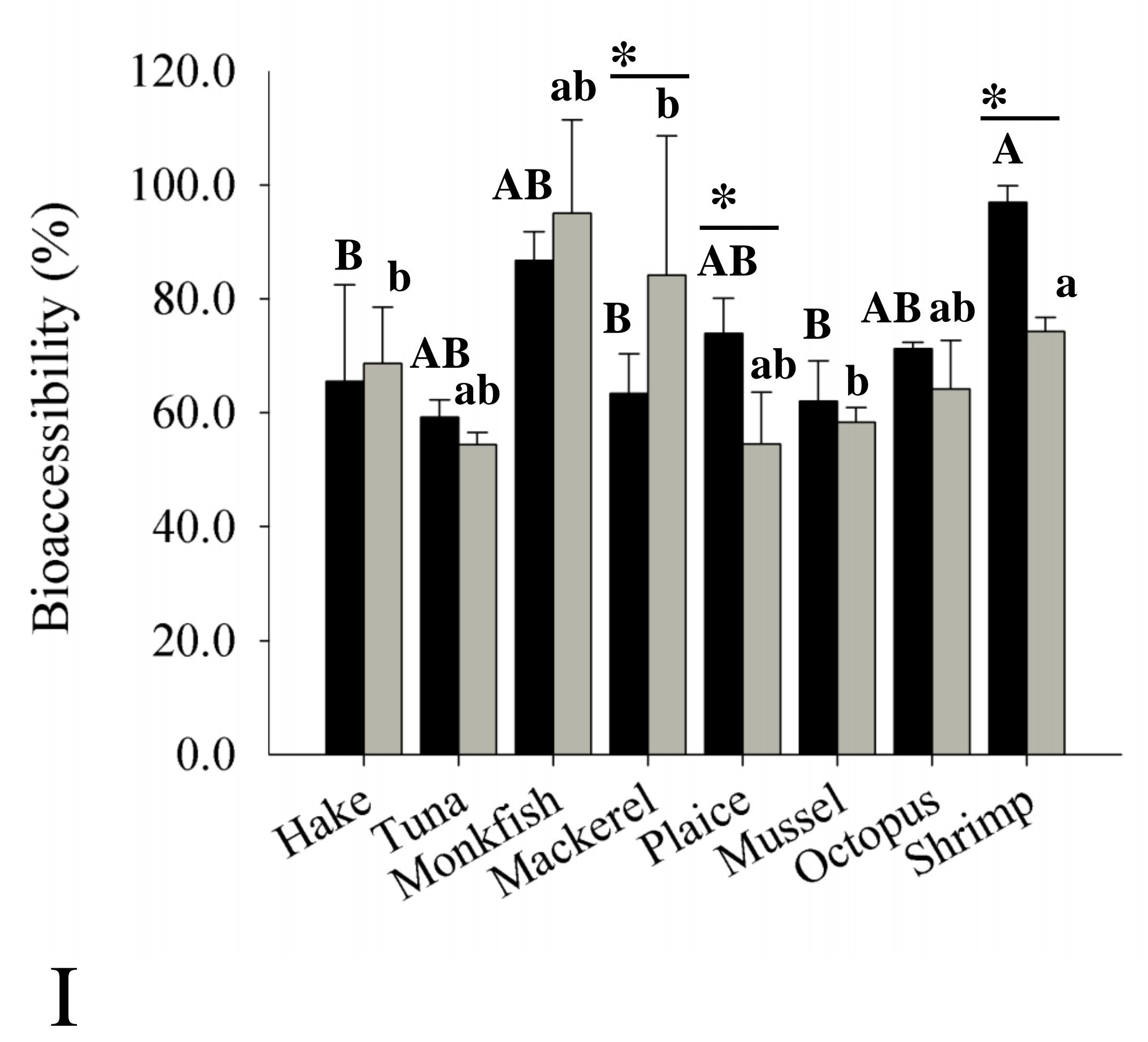

Strontium

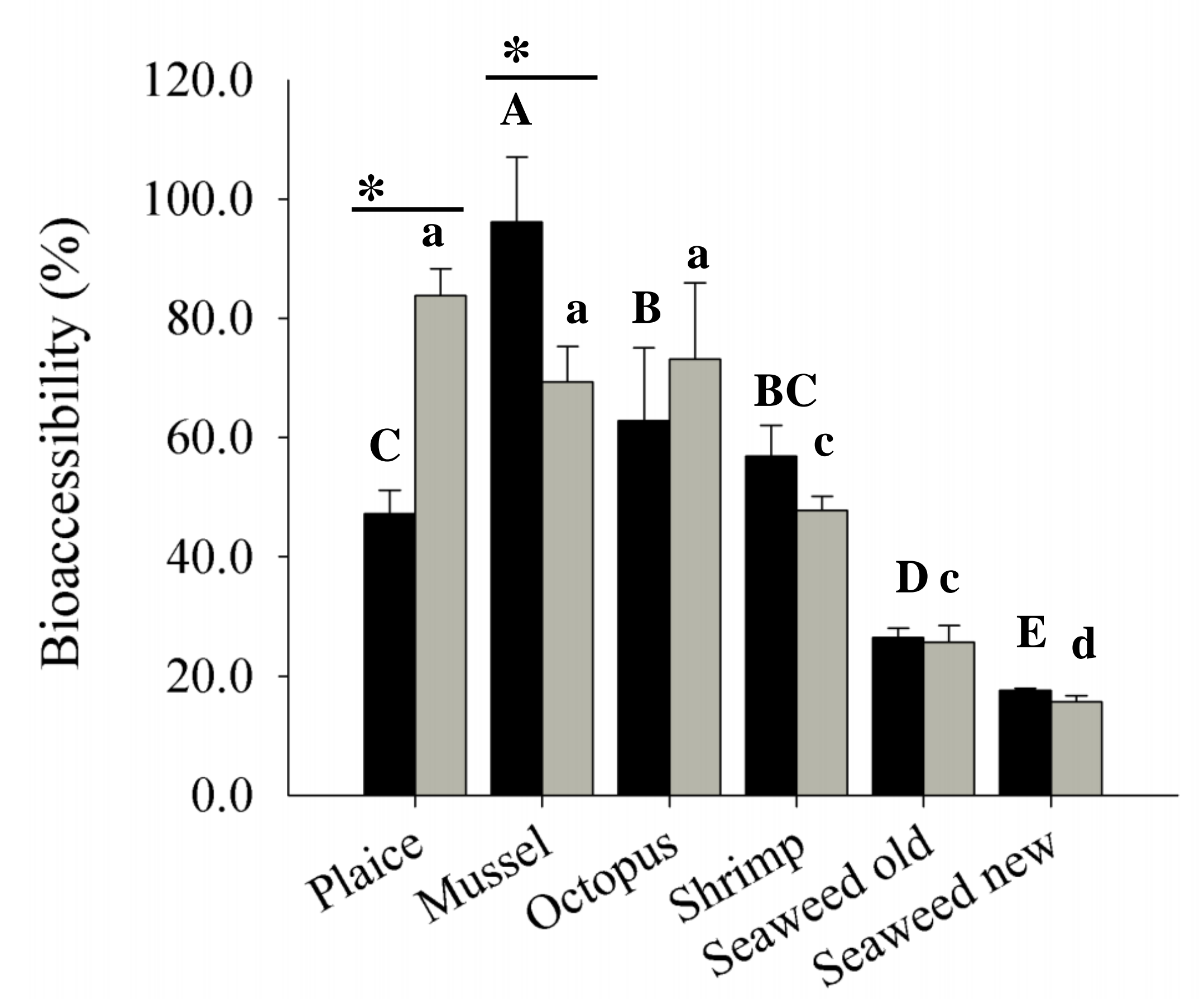

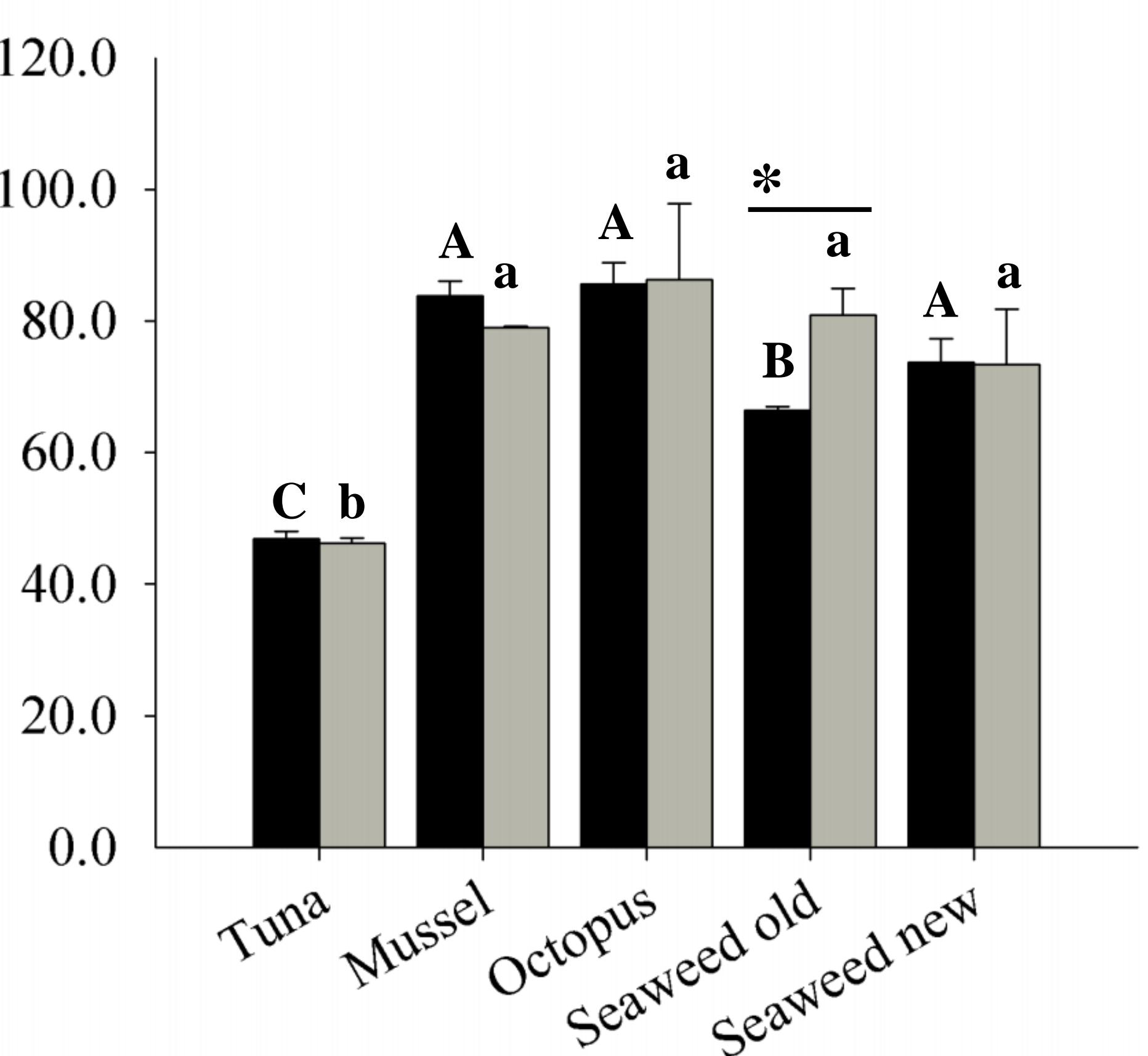


Supplemental Figure 1
Click here to download Supplemental: Supplemental Fig.1.pdf

Click here to download Supplemental: Supplemental Fig.1.pdf

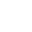

(n)

$\sqrt{2}$

.

(1)

(1)

(1)

(1)

(1)

(1)

(1)

.

.

.

.

.

.

.

.

.

.

.

.

.

.

.

.

.

.

.

.

.

.

.

.

.

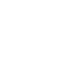


Supplemental Table 1
Click here to download

Click here to download Supplemental: Supplemental table 1.docx

Click here to download Supplemental: Supplemental table 1.docx

pplemental: Supplemental table 1.docx

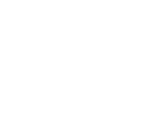

-

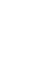

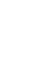
.

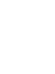

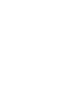
.

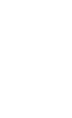

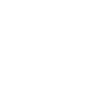

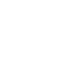

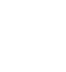

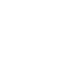

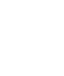

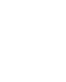

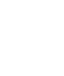

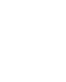

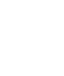

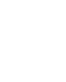

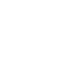

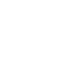
更

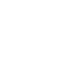

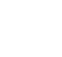


Supplemental Table 2
Click here to download Supplemental: Supplemental Table 2.docx

Supplemental Table 2
Click here to download Supplemental: Supplemental Table 2.docx

X

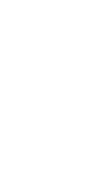
$\left(\frac{10}{0}\right.$

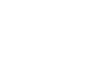

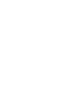

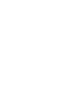

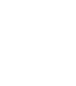
. .

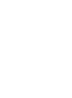
. . . 
Supplemental Table 3
Click here to download

Click here to download Supplemental: Supplemental Table 3.docx

\begin{abstract}
Click here to download Supplemental: Supplemental Table 3. docx
\end{abstract}
(1)

(1)

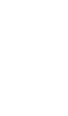

(1)

(1)

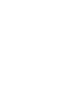

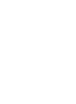

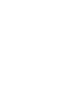

(1) 
Supplemental Table 4
Click here to download Supplemental: Supplemental Table 4.docx

Supplemental Table 4
Click here to download Supplemental: Supplemental Table 4.docx

Supplemental Table 4
Click here to download Supplemental: Supplemental Table 4.docx

$(2+2$

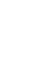
( (

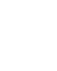
( ( .

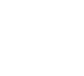

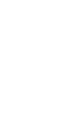
更 更 更 更 更 更 更 更 更 更 更 更 更 更 
Supplemental Table 5
Click here to download Supplemental: Supplemental Table 5.docx

Supplemental Table 5
Click here to download Supplemental: Supplemental Table 5.docx 
Supplemental Table 6
Click here to download Supplemental: Supplemental table 6.docx

Supplemental Table 6
Click here to download Supplemental: Supplemental table 6.docx

\begin{abstract}
Click here to download Supplemental: Supplemental table $6 . d 0 c x$
\end{abstract}
(

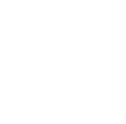

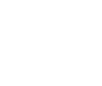

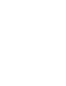

(2)

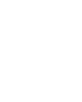

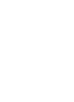

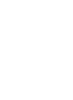
. .

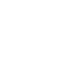

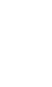

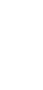
.

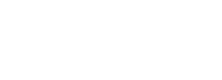

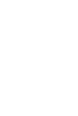

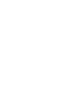
.

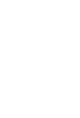
.

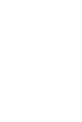
. . . .

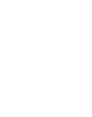

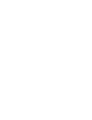

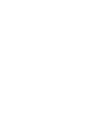

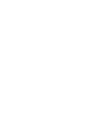

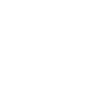

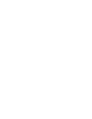
.
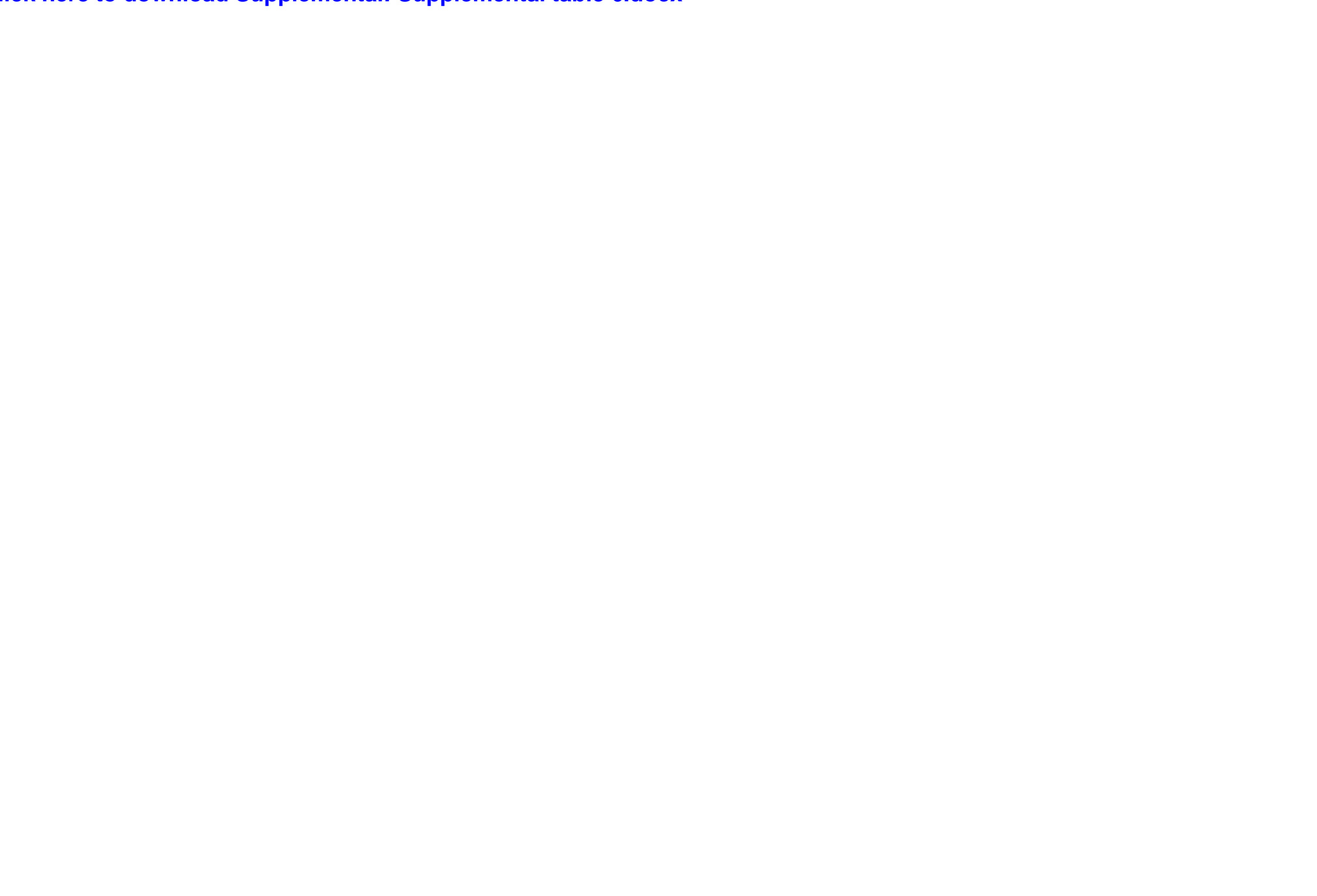